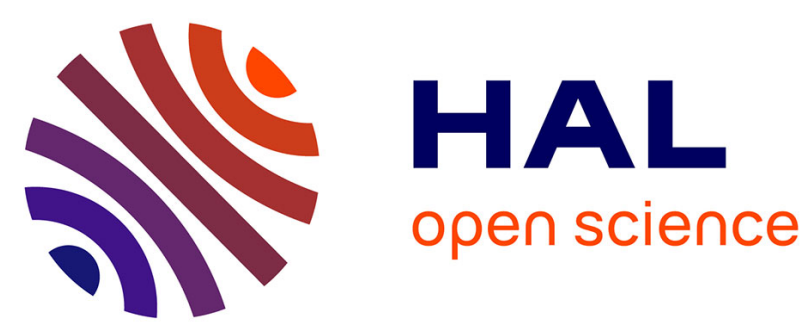

\title{
Experimental study of thrust force and surface quality when drilling hybrid stacks
}

Amani Mahdi, Yosra Turki, Malek Habak, Mehdi Salem, Zoubeir Bouaziz

\section{To cite this version:}

Amani Mahdi, Yosra Turki, Malek Habak, Mehdi Salem, Zoubeir Bouaziz. Experimental study of thrust force and surface quality when drilling hybrid stacks. International Journal of Advanced Manufacturing Technology, 2020, 107, pp.3981-3994. 10.1007/s00170-020-05252-7 . hal-02562361

\section{HAL Id: hal-02562361 https://imt-mines-albi.hal.science/hal-02562361}

Submitted on 16 Sep 2020

HAL is a multi-disciplinary open access archive for the deposit and dissemination of scientific research documents, whether they are published or not. The documents may come from teaching and research institutions in France or abroad, or from public or private research centers.
L'archive ouverte pluridisciplinaire HAL, est destinée au dépôt et à la diffusion de documents scientifiques de niveau recherche, publiés ou non, émanant des établissements d'enseignement et de recherche français ou étrangers, des laboratoires publics ou privés. 


\title{
Experimental study of thrust force and surface quality when drilling hybrid stacks
}

\author{
Amani Mahdi ${ }^{1}$ (D) $\cdot$ Yosra Turki $^{1} \cdot$ Malek Habak $^{2} \cdot$ Mehdi Salem $^{3} \cdot$ Zoubeir Bouaziz $^{1}$
}

\begin{abstract}
Increasing aircrafts' productivity and reducing their riveting time have created the need of one-shot drilling of dissimilar materials. The present work had followed this strategy on 4 shaft satin weave carbon fiber and epoxy matrix (AS-4 woven CFRP) and aluminum alloy (AA 2189) in order to study the effect of drilling direction on $\mathrm{Al}$ and carbon fiber reinforced polymer thrust force evolution and holes' quality. It presents a comparison between CFRP, CFRP/Al, and Al/CFRP results using the same drilling tool and cutting parameters to understand the influence of adding metal layers on CFRP drilling defects. It was observed that the increase of the thrust force is related to cutting parameters. It causes thermal degradation of composite matrix when drilling CFRP/Al, and it impacts the aluminum surface roughness. One-shot drilling strategy does not affect thrust force evolution whenever the layers' position in the stack. Drilling defects exist especially in the composite part such as uncut fibers, chipping, and spalling. It was found that the cutting speed had the dominant influence on surface damage. Holes' quality differs from one configuration to another. Adding $\mathrm{Al}$ layer on the top reduces seriously the composite drilling defects and causes groove in the $\mathrm{Al}$ holes. Composite matrix smearing was observed when drilling CFRP/Al. It seems that drilling CFRP sheet between to supports improves composite holes' quality.
\end{abstract}

Keywords Woven CFRP $\cdot$ Al alloy $\cdot$ Drilling $\cdot$ Delamination $\cdot$ Thrust force $\cdot$ Surface quality

Amani Mahdi

amani.mahdi@enis.tn

Yosra Turki

yosra.turki@hotmail.fr

Malek Habak

malek.habak@u-picardie.fr

Mehdi Salem

mehdi.salem@mines-albi.fr

Zoubeir Bouaziz

zoubeir.bouaziz@enis.rnu.tn

1 Laboratory of Applied Fluid Mechanics, Environment and Process Engineering "LR11ES57", National School of Engineers of Sfax, University of Sfax, Route Soukra Km 3.5, 3038 Sfax, Tunisia

2 Laboratory of Innovative Technology "LTI", University of Picardie Jules Verne, Avenue des Facultés Le Bailly, 80001 Cedex 1 Amiens, France

3 Toulouse University, CNRS, Mines Albi, INSA, UPS, ISAE-SUPAERO, ICA (Institut Clément Ader), Campus Jarlard, F-81013 Albi, France

\section{Introduction}

In recent years, the use of composite materials has been increasing in aerospace, aeronautic, naval, and automotive industries. Carbon fiber reinforced polymer (CFRP) has been a key material in many applications due to its excellent attributes such as low weight, excellent fatigue and corrosion resistance, and high strength and chemical resistance $[1,2]$. CFRPs have been one of the most used in the manufacturing of aircrafts. Fifty percent composites, $20 \% \mathrm{Al}, 15 \% \mathrm{Ti}, 10 \%$ steel, and $5 \%$ other materials were used in the manufacture of the Boeing 787 Dreamliner [3]. Woven CFRP has been also used in aerospace and structures such as rocket engines because of its high aeronautic application especially in hot parts of thermal protection and its ability to drape curved surfaces without wrinkling [4]. Making holes in CFRP are made for structure joining. This operation is made in particular conditions to avoid damages during processing such as delamination, spalling, chipping, and uncut fibers [5]. Many researchers have studied the process of drilling CFRP. Qui et al. [6] have treated the influence of machining parameters and tool geometry on cutting force and hole wall damage 
when drilling unidirectional CFRP with twist and stepped drills. They have noted that low feed rate and the use of stepped drill reduce the risk of delamination. Similar tests were carried out on unidirectional CFRP in many other researchers' work [7, 8]. Drilling operations of bidirectional carbon fiber-reinforced epoxy matrix (BCFREC) have also motivated the development of different studies. We have studied in our previous work the influence of cutting parameters and the tool geometry on drilling AS-4 woven CFRP [9]. We have noted that the tool geometry and the feed rate were the most responsible ones of the thrust force augmentation and delamination phenomenon. Spur drill bit gave the best results compared with twist drill bit. In the commercial aircraft, CFRP parts are stacked with metallic alloys especially in the skin and the wing segments and the fuselage. For example, in Airbus A350XWB, fuselage frames are made with aluminum, and rear fuselage section is made with carbon fiber composite [10]. The existence of different parts, made with different materials and joined together in aerostructure, has also given birth the idea of drilling them at the same time to minimize the manufacturing cost and to improve the manufacturing quality and efficiency of aircrafts. However, the drilling of hybrid composite metallic structures is not easy enough. The mechanical proprieties of these two materials and their interaction with the drilling tool are very far apart. The interface region between CFRP and metal sheets, like in CFRP/Al or CFRP/Ti stacks, has been the most defective area. In fact, the cutting edges drill the two materials at the same time, and it has caused drilling defects like delamination, burr, interlayer chip, and hole surface damages due to high temperature [11, 12]. The stacked composite metal is regarded nowadays as a new material called carbon fiber reinforced polymer and metal stacks (CMSs) [13]. In the literature, limited researchers have been carried out on the machining of CMS. The whole idea was to establish solutions to avoid defects in the interface region between different materials. Fernandez-Vidad et al. [14] have detailed a comparison between the drilling of unidirectional CFRP and Al plates separately or stacked together. They have noted the acting tool wear mechanisms differ greatly when drilling each material separately or together. Indeed, they have shown that drilling $\mathrm{CFRP} / \mathrm{Al}$ causes the domination of bond wears over surface tool abrasion. $\mathrm{MH}$ et al. [15] have studied the effects of twist drill geometry and drilling parameters on unidirectional CFRP/Al stack up in single-shot drilling by using Electronic Pneumatic Advanced Drilling Unit. They have noted that the increasing of point angle, chisel edge angle and speed contributed a large difference in diameter for CFRP and Al materials. However, this deference was decreased when there was an increment in helix angle, primary clearance angle, and feed rate. For the minimum burr height formation, the suitable drilling and geometry parameters were at higher feed rate and point angle value. El Bouami et al. [16] have studied the influence of machining parameters and tool structure on cutting force and hole wall damage in drilling unidirectional CFRP/Al stacks. They have noted that the quality of the machined surfaces and also the tool wear are directly linked to the drilling parameters. Indeed, the combination of low feed rates and optimal coated tool geometry have provided good results in terms of thrust force reduction and delamination phenomenon minimization. They have also noted in previous work [17] that the drilling of CFRP/Al stacks demanded higher value of feed rate because it led to break up the chips, to avoid the creation of burrs, and to preserve the drill's integrity. However, with this condition, CFRPdrilled holes have suffered from serious drilling defects such as delamination and tearing of fibers. The study of Wang et al. [3] has been conducted to understand the influence of drilling temperature, cutting parameters, and hole quality on drilling unidirectional CFRP/Al stacks using diamondcoated drill. They have noted that the measured CFRP hole diameter was always larger than that measured in the $\mathrm{Al}$ hole due to the increase of tool instability as drilling of the Al layer. The highest spindle speed could also achieve a smaller diameter difference between CFRP and Al holes. Indeed, the drilling temperature has increased with the increase of spindle speed, and it has decreased with the increase of feed rate. Low values of feed rate have also attributed to the difficult evacuation of the long and flexible Al chips. Although many research studies have been carried out on the effect of drilling conditions on CFRP and metal holes' surface quality in CFRP/metal stacks, few have been investigated the drilling process of metal/CFRP stacks through experimental testing $[18,19]$. The studies mentioned above discuss the variation of the thrust force and torque generated during drilling process of $\mathrm{Al} / \mathrm{CFRP}$ and identify the best combination of cutting speed and feed rate based on thermographic study of the process. But they make no assumptions about the surface quality of drilled holes using microscopic and SEM observations. The present work investigates the influence of adding metal layers to hybrid stacks at various positions on drilling defects. It presents a detailed comparison between the effects of changing the drilling direction on holes' quality in each material. In order to minimize the apparition of drilling defects and to choose the best drilling direction of hybrid stacks, the result can be extended by using advanced mathematical modeling and optimization methods such as analysis of variance methodology, artificial neural networks, and genetic algorithms [20-23]. In this study, the selected hybrid stacks are composed of two materials utilized nowadays in the construction of aircraft fuselage and multicopters, and it is named as AS4 woven CFRP and AA 2189. The choice of woven composite in our study is based to its large application in aerospace industry using prepreg/autoclave method because of 
its good tenacity, its easy drapability, and its low cost compared unidirectional composite. This type of satin is also utilized in aircraft manufacturing because of its smoothness, its good drape, and its low porosity and crimp compared with other fabrics. AS-4 woven CFRP sheet was also drilling using the same drilling conditions of drilling AA 2189/AS-4 woven CFRP stack to investigate the influence of $\mathrm{Al}$ position in the hybrid stack on the studied phenomena mentioned above. CFRP inside holes were visualized using SEM observation to estimate the influence of drilling conditions on interior CFRP drilling defects.

\section{Experimental work}

\subsection{Workpiece material and drills}

Experimental drilling tests were carried out on two hybrid stacks and a woven CFRP sheet. Al/CFRP and CFRP/Al stacks are obtained using AA 2198 and AS-4 woven CFRP plates which are closely assembled through four bolts. This type of composite is selected because of its high strength fibers and its large application in aerospace industry especially at fuselage frames and multicopters. Referenced aluminum plate is also utilized in aerospace industry. Woven CFRP plate is composed of 18 plies with the same orientation of weaving. CFRP sheet is composed of M26T prepreg Matrices HexPly and Balanced Fabrics G0939/G0802 style. It was manufactured by Hexcel composites, and it was made by Zodiac Aerospace using prepreg/autoclave technique. The size of the stack plate is $100 \mathrm{~mm} \times 100 \mathrm{~mm} \times 7.6 \mathrm{~mm}$. The thickness of woven CFRP and aluminum alloy is 4.6 and $3 \mathrm{~mm}$, respectively, as indicated in Fig. 1 which illustrates the schematic of the CFRP/Al section. Drilling process without lubrication has been utilized using uncoated twist carbide drill as shown in Fig. 2. Special composite drills such as spur drills are not suitable for drilling hybrid stacks as indicated in the literature [24]. Otherwise, normal twist drills are the most used ones by researchers to drill composite/metal stacks [25-27]. The utilized uncoated twist drill is characterized by a nominal diameter equal to $6.3 \mathrm{~mm}$. It has $120^{\circ}$-point angle, $5^{\circ}$ cutting angle, $11^{\circ} \mathrm{draft}$ angle, and $30^{\circ}$ helix angle.

\subsection{Machining tests}

The drilling tests were performed on a numerical-controlled Charlyrobot CPR0705 machine. During the drilling process, the drilled material was fixed on a support including holes with $7 \mathrm{~mm}$ diameter. The support holes' diameter is slightly larger than drill's diameter in order to drill though the holes in the stack without touching the support. Indeed, this kind of support decreases the bending of drilled material and allows the produce of drilling defects at the hole's exit side as if the stack was drilled without support. The used drilling mode in this study was without lubrication to avoid the pollution of the material. That is why the use of a vacuum cleaner is essential. Figure 3 illustrates the schematic diagram of the experimental setup in the case of drilling CFRP/Al stack. Kistler 9257B dynamometer plate was used to record the thrust force $F_{z}$. It was fixed under the support. The results are obtained using Kistler Dynoware software 2825D. Caggiano et al. [18] reported that the use of high values of cutting parameters may break the tool. High values of feed rate and spindle speed are not suitable for drilling Al/CFRP stack. Based on this remark, the performance of the Charlyrobot and the mechanical proprieties of the two chosen materials, the cutting parameters (feed rate $V_{\mathrm{f}}$ and cutting speed $V_{\mathrm{c}}$ ) were selected and summarized in Table 1. Holes' macroscopic observations were made using Leica binocular loupe. Holes quality was evaluated in terms of delamination holes size and surface roughness. Delamination was assessed on entry and exit sides of woven CFRP plate.

The ratio of damaged diameter over the hole diameter was used to calculate the delamination factor $F_{\mathrm{d}}$ as shown in Eq. (1). An example of delamination specimen for the calculation of $F_{\mathrm{d}}$ is presented in Fig. 4. Holes inside quality were studied by macroscopic observations. SEM observations were carried out to understand the impact of the metal part on composite one when drilling CFRP/Al and Al/CFRP stacks. CFRP and Al holes' size was measured using a micrometer 3P15 (Swiss made). The Al hole's surface roughness $R_{\mathrm{a}}$ was measured using Mitutoyo S.J.201 M following the 0.8-mm stroke.

$$
F_{\mathrm{d}}=\frac{D_{\mathrm{d}}}{D_{n}}
$$

where $D_{\mathrm{d}}$ is damage diameter and $D_{\mathrm{n}}$ is hole nominal diameter.
Fig. 1 Schematic of the CFRP/Al stack section

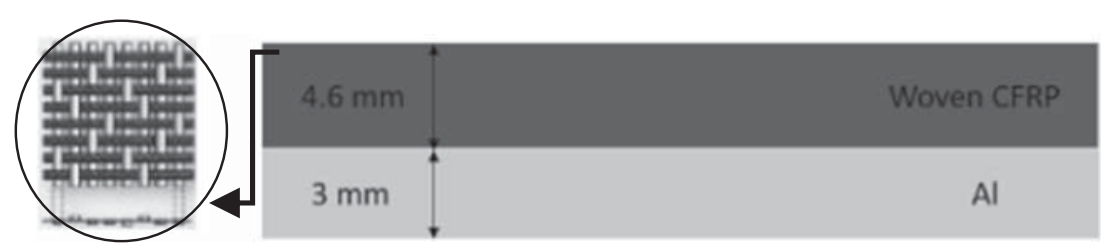

AS-4 woven 

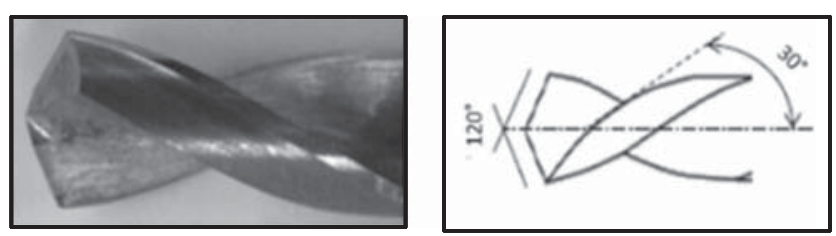

Fig. 2 Twist carbide drill

\section{Results and discussion}

\subsection{Thrust force}

The experimental curve of thrust force, which is captured by Kistler 9257B plate when drilling CFRP/Al stack, is shown in Fig. 5. It presents the relation between the thrust force $F_{\mathrm{z}}$ and the position of the tool's active part in the CFRP/Al stack using a feed rate equal to $15 \mathrm{~mm} / \mathrm{min}$ and a cutting speed equal to $59.346 \mathrm{~m} / \mathrm{min}$. At the beginning, $F_{\mathrm{z}}$ is equal to $0 \mathrm{~N}$. When the tool's tip touches the CFRP plate, the thrust force increases in a linear manner until it goes through the top face of the sheet. In this case, the constant pressure exerted by the tool tip on the workpiece leads to have a cutting force equal to the pushing force. As long as the drill's cutting part is emerged in the composite sheet, the thrust force value is nearly constant. When the cutter moved down to exit the woven CFRP plate, it touches the Al plate and goes to penetrate the second sheet. The value of the thrust force increases suddenly, and it becomes nearly constant after the same process. Due to the difference between $\mathrm{Al}$ and CFRP characteristics, $F_{\mathrm{z}}$ is higher in the Al sheet than in the woven CFRP sheet. After that, the value of the thrust force decreases linearly until it reaches zero when the tool's active part is exiting the CFRP/Al stack [12]. Same reasoning between the evolution of $F_{\mathrm{z}}$ and the tool's active part position in the drilled material is applied in the case of Al/CFRP stack and CFRP sheet.

The evolution of the thrust force $F_{\mathrm{z}}$, which is recorded during the drilling of CFRP sheet, CFRP/Al, and Al/CFRP stacks as a function of feed rate $V_{\mathrm{f}}$ and cutting speed $V_{\mathrm{c}}$, is presented in Fig. 6. On one hand, taking into account that the Kistler dynamometer measures $F_{\mathrm{z}}$ value with an error interval equal to $5 \mathrm{~N}$, it seems that changing materials' order in drilled stack does not affect $F_{\mathrm{z}}$. Indeed, the existence or the absence of $\mathrm{Al}$ sheet in the stack does not affect $F_{\mathrm{z}}$ CFRP values. This seems logical because the variation of $F_{z}$ depend essentially of tool's geometry and drilled material using the same cutting parameters. Moreover, $F_{\mathrm{z}}$ recorded during the drilling of $\mathrm{Al}$ was found to be two times higher than those recorded during the drilling of woven CFRP. Indeed, the thrust force increases sharply when the drill starts to enter $\mathrm{Al}$ sheet. This phenomenon is due to the sudden change in material hardness of $\mathrm{Al}$ plate compared with woven CFRP [24]. On the other hand, regarding Fig. $6 \mathrm{a}, F_{\mathrm{z}}$ is slightly elevated with the increase of $V_{\mathrm{f}}$ in the case of woven CFRP and Al. An increase of $40 \%$ in the $V_{\mathrm{f}}$ value increases the $F_{\mathrm{z}}$ value with an average of percentage near to 6 and $3 \%$ in the case of woven CFRP and Al, respectively. However, this slight elevation is neglected compared with the dynamometer error measurement. These results are explained by the use of low feed rates generally used in grinding process. Regarding Fig. $6 \mathrm{~b}$, the increase of $V_{\mathrm{c}}$ reduces the value of $F_{z}$ when drilling woven CFRP due to cutting edges temperature rise which reduces the cutting resistance of epoxy matrix [28]. Indeed, increased $V_{\mathrm{c}}$ decreases slightly $F_{\mathrm{z}}$ while drilling $\mathrm{Al}$ because the increase of $V_{\mathrm{c}}$ increases the drilling temperature which causes the deterioration of the Al properties. An increase of $50 \%$ in the $V_{\mathrm{c}}$ value leads to a decrease of approximately 34 and $15 \%$ in the $F_{\mathrm{z}}$ value in the case of woven CFRP and Al, respectively. For example, while drilling with a feed rate of $15 \mathrm{~mm} / \mathrm{min}$, the value of the thrust force decreased from 50 to $28 \mathrm{~N}$ in the case of woven CFRP and from 67 to $54 \mathrm{~N}$ in the case Al when drilling CFRP/Al stack. Therefore, in our case, cutting speed is the most important factor influencing the thrust force no matter for woven CFRP or Al compared with feed rate.

\subsection{Drilled holes quality}

Drilled holes' diameters of aluminum and composite parts in CFRP/Al, Al/CFRP stacks, and CFRP sheet were controlled by employing a 3-point internal micrometer 3P15 in order to investigate the effect of cutting parameters on diameter difference. Measures were repeated four times at four different holes' angle locations, and the average of these repeated measures was taken as a final result. In the literature, there is a large difference between holes' diameters among different layers in hybrid stacks due to the difference of mechanical and physical proprieties in each material [3]. However, in our case, their values are practically similar, and the difference
Fig. 3 Schematic diagram of the experimental setup

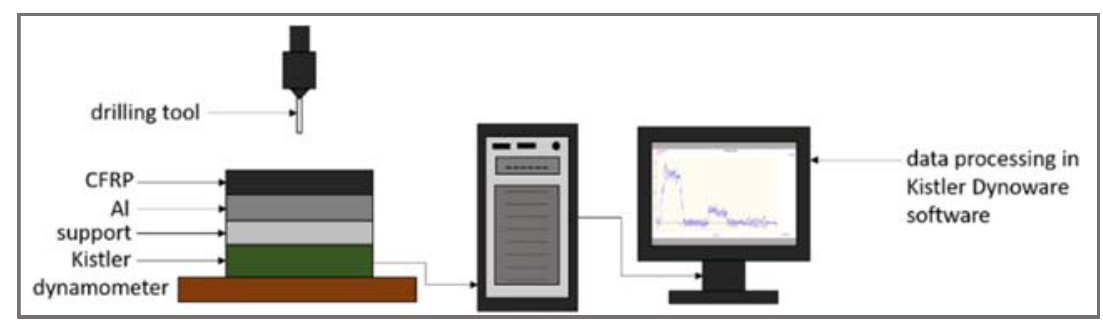


Table 1 Cutting parameters used in drilling tests

\begin{tabular}{lc}
\hline$V_{\mathrm{f}}(\mathrm{mm} / \mathrm{min})$ & $V_{\mathrm{c}}(\mathrm{m} / \mathrm{min})$ \\
\hline 9 & 59,346 \\
15 & 118,692 \\
21 & 178,038 \\
\hline
\end{tabular}

of holes' diameters between $\mathrm{Al}$ and woven CFRP plates is neglected in the case of CFRP/Al and Al/CFRP stacks. The error is near to $0.1 \%$ between aluminum and composite parts. Indeed, by varying the machining parameters, the hole's diameter remains constant for each material. The error is near to 0.6 and $0.7 \%$ compared with tool diameter for woven CFRP and $\mathrm{Al}$, respectively, in CFRP sheet, $\mathrm{CFRP} / \mathrm{Al}$, and $\mathrm{Al} / \mathrm{CFRP}$ stacks. This great quality of holes' diameters for both $\mathrm{Al}$ and CFRP parts is explained by the use of low values of feed rate. In order to understand the influence of adding Al layer at different positions on CFRP holes' quality, the study of delamination phenomenon is necessary. This kind of defects, which is not clear to the naked eye, is reported to be the most reason of composite parts' rejection in drilling. Delamination factor was calculated based on macroscopic observation of woven CFRP holes in the drilled stacks and sheet. $F_{\mathrm{d}}$ values were summarized in Fig. 7. During the drilling operation, continuous aluminum chips were produced. In the literature, the cumming out of Al chips affects the hole CFRP entry when drilling CFRP/Al stack [28]. However, in our case, the delamination phenomenon is neglected at the entrance side especially in woven CFRP sheet and CFRP/Al stack due to the low obtained values of the delamination factor. In the case of Al/CFRP stack, it is slightly increased compared with CFRP sheet and CFRP/Al stack because the generated surface of composite material is located between aluminum and composite layers. Regarding this stack in itself, it seems that delamination phenomenon at the entrance side of composite part is mainly connected to difficulties in heat generation caused

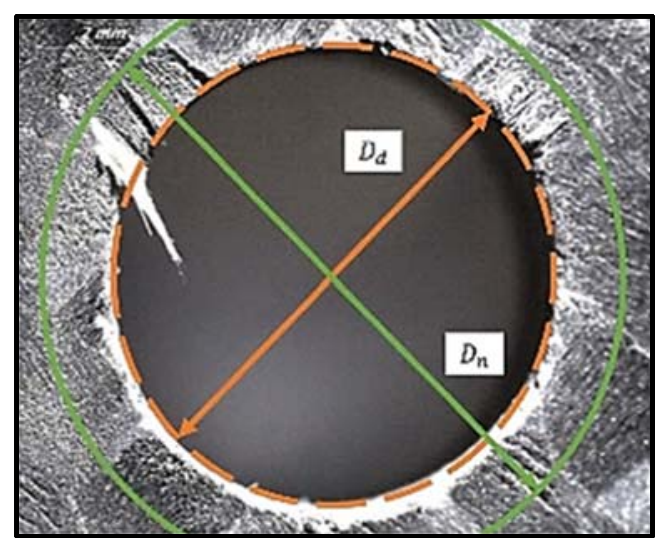

Fig. 4 Example of delamination specimen to calculate the delamination factor

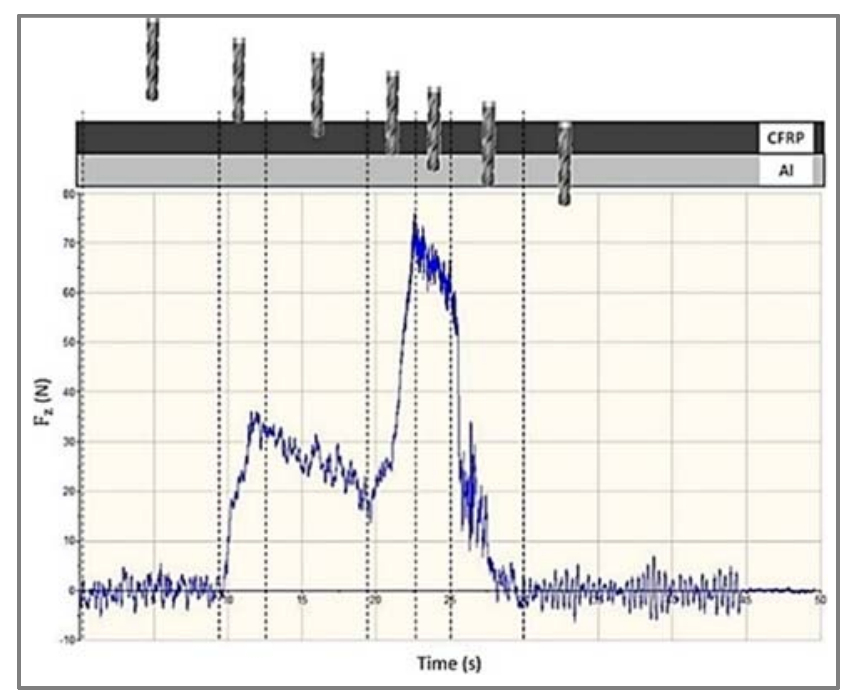

Fig. 5 Recorded $F_{\mathrm{z}}$ during the drilling of CFRP/Al

by Al part [29]. However, the cutting parameters do not influence the delamination factor at the entrance side of woven CFRP whatever the stacking. Concerning the exit side of composite part, the delamination phenomenon is seriously presented especially in woven CFRP sheet compared with CFRP/Al and $\mathrm{Al} / \mathrm{CFRP}$ stacks. It can be noted that the presence of $\mathrm{Al}$ sheet above or below the CFRP layer may reduce briefly the delamination phenomenon at the exit side of woven CFRP part. In our case, the lowest values of $F_{\mathrm{d}}$ is related to $\mathrm{Al} /$ CFRP stack. In other words, the quality of the composite exit area is significantly improved without the Al layer support due to the efficient evacuation of $\mathrm{Al}$ chips from the hole. When drilling from CFRP out to $\mathrm{Al}$ layer, the $\mathrm{Al}$ chip would be occurred and accumulated in the spiral grooves and rotate with the drill bit. It may erode the matrix resin and edge delamination problem at CFRP hole's exit side [3]. Indeed, the presence of Al layer on the top of woven CFRP layer decreases more the bending of composite part compared with its absence. In other to say, fixing the composite plate between two supports (Al layer and the utilized support) is more robust than fixing it on one support. The variation of feed rate influences also $F_{\mathrm{d}}$ at the exit side of composite part. At low value of feed rate, almost a perfect hole is observed. Indeed, the value of delamination factor increases with $V_{\mathrm{f}}$. For example, when drilling CFRP sheet, an increase of $40 \%$ in the $V_{\mathrm{f}}$ value increases the $F_{\mathrm{d}}$ value from 1.33 to 1.54 . However, the variation of cutting speed $V_{\mathrm{c}}$ does not have significant effect. Its increase generates a slight increase of $F_{\mathrm{d}}$. The highest damage was recorded when using $V_{\mathrm{f}}=21 \mathrm{~mm} / \mathrm{min}$ and $V_{\mathrm{c}}=178.038 \mathrm{~m} / \mathrm{min}$. The best results were achieved using $V_{\mathrm{f}}=9 \mathrm{~mm} / \mathrm{min}$ and $V_{\mathrm{c}}=$ $178.038 \mathrm{~m} / \mathrm{min}$. Based on the works of Turki et al. [30] and Ashrafi et al. [24], we notice that the cutting parameters have the same influence on the delamination factor when drilling unidirectional CFRP. Macroscopic observation of holes' external surfaces showed also other types of drilling defects 


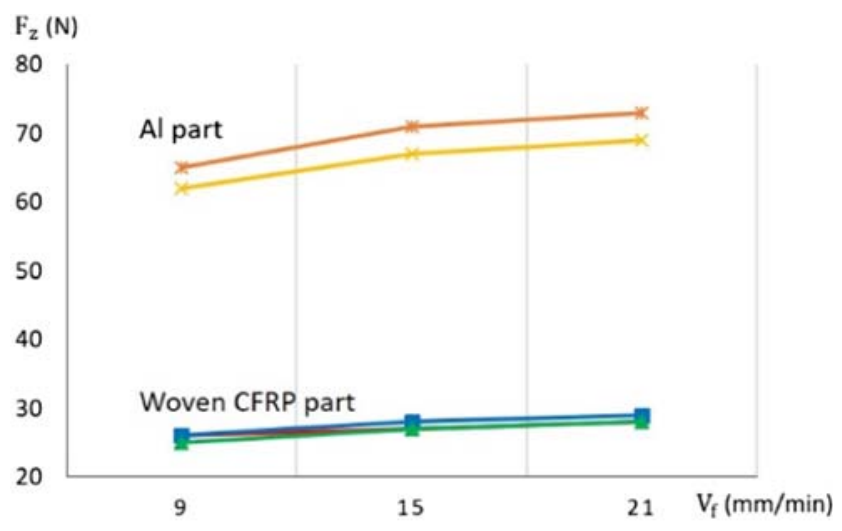

(a) $F_{z}=f\left(V_{f}\right)$ at $V_{c}=178.038 \mathrm{~m} / \mathrm{min}$

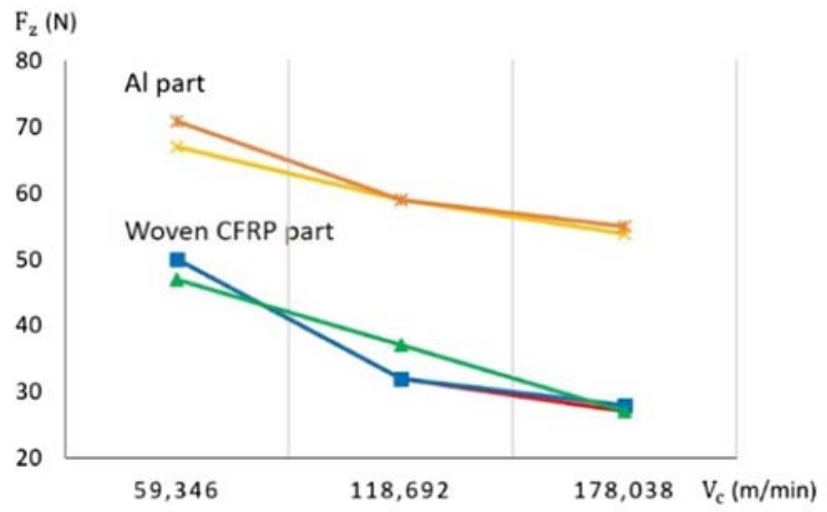

(b) $F_{\mathrm{z}}=\mathrm{f}\left(\mathrm{V}_{\mathrm{c}}\right)$ at $\mathrm{V}_{\mathrm{f}}=15 \mathrm{~mm} / \mathrm{min}$

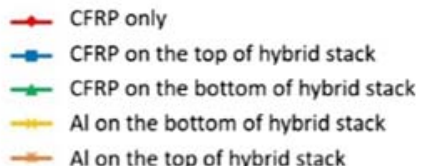

Fig. 6 Variation of $F_{\mathrm{z}}$ at various $V_{\mathrm{c}}$ and $V_{\mathrm{f}}$. (a) $F_{\mathrm{z}}=\mathrm{f}\left(V_{\mathrm{f}}\right)$ at $V_{\mathrm{c}}=$ $178.038 \mathrm{~m} / \mathrm{min}$; (b) $F_{z}=\mathrm{f}\left(V_{c}\right)$ at $V_{f}=15 \mathrm{~mm} / \mathrm{min}$

related to the hole quality in $\mathrm{Al}$ and woven CFRP plates whenever the experiments started from the CFRP layer to the $\mathrm{Al}$ or vice versa, or it was carried on CFRP only. Figure 8 illustrates the entrance and the exit holes' sides for both woven CFRP and $\mathrm{Al}$ plates using a scale of $2 \mathrm{~mm}$ at various cutting speed $V_{\mathrm{c}}$ and feed rate $V_{\mathrm{f}}$ when drilling CFRP sheet, CFRP/Al, and $\mathrm{Al} /$ CFRP stacks. Regarding the composite part, there are four types of drilling defects. We can see fraying which is presented by the existence of uncut fibers in the hole area, chipping which is a mark made by the drilling operation, spalling which is a delamination accompanied by tearing of a piece of ply and fuzzing which is presented by a thermal degradation of the matrix resin at the edge of the holes [5]. Fraying is sometimes accompanied by chipping. Drilling defects exist especially in the exit side of woven CFRP holes. It can be noted that

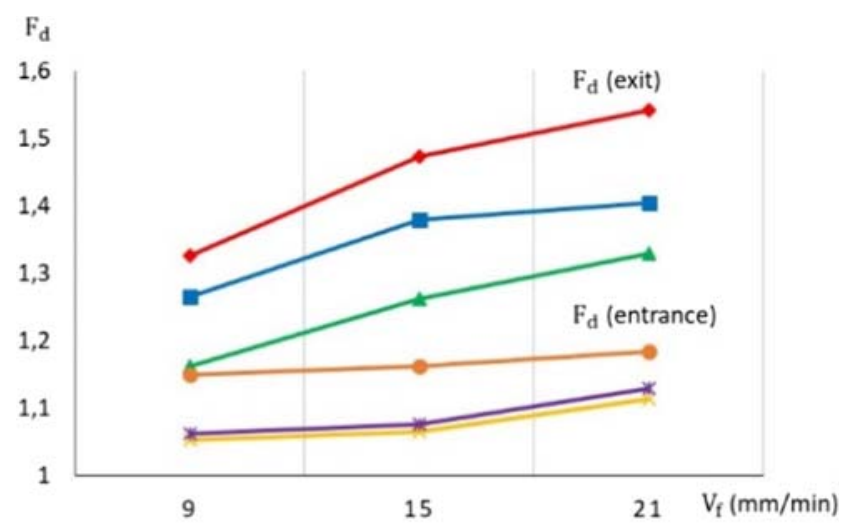

(a) Variation of $F_{d}$ at $V_{c}=178.038 \mathrm{~m} / \mathrm{min}$

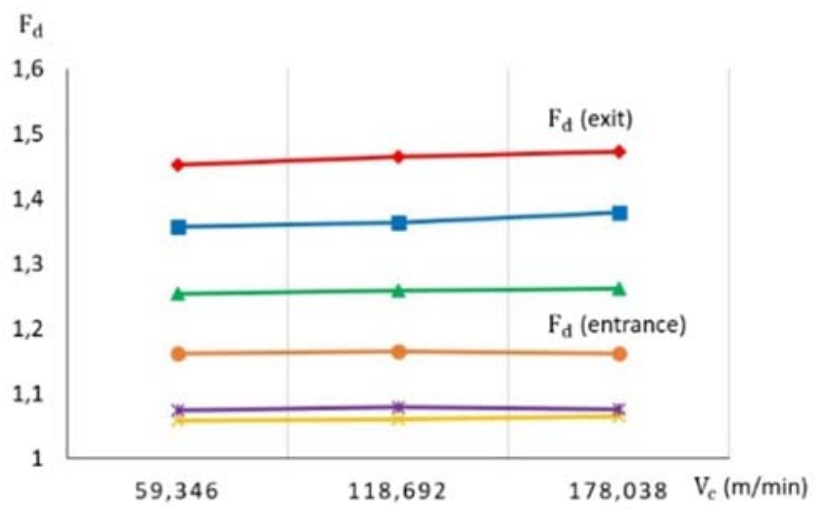

(b) Variation of $F_{d}$ at $V_{f}=15 \mathrm{~mm} / \mathrm{min}$

$$
\begin{aligned}
& -1-\text { CFRP only } \\
& -1-\text { CFRP on the top of hybrid stack } \\
& -1-\text { CFRP on the bottom of hybrid stack }
\end{aligned}
$$

Fig. 7 Variation of $F_{\mathrm{d}}$ at various $V_{\mathrm{c}}$ and $V_{\mathrm{f}}$. a Variation of $F_{\mathrm{d}}$ at $V_{\mathrm{c}}=$ $178.038 \mathrm{~m} / \mathrm{min}$. b Variation of $F_{\mathrm{d}}$ at $V_{\mathrm{f}}=15 \mathrm{~mm} / \mathrm{min}$

fraying, chipping, and spalling exist whenever drilling composite or aluminum layer first. The main reason of the apparition of those defects is the interaction between the cutting edge and the drilled material [31]. These surface damages are more likely presented in the case of CFRP sheet compared with CFRP/Al and Al/CFRP stacks. The existence of Al layer on the top or on the bottom of woven CFRP may reduce the appearance chronology of different types of surface damages according to interlaminar crack propagation mode: mode I, mode II, or mixed mode I + II [32]. Indeed, when drilling from the Al layer, the composite hole quality is significantly improved compared with other cases. The observed damages are the same as obtained in several research works such as Turki at al. [8] in the case of drilling unidirectional CFRP and Feito et al. [5] in the case of drilling woven CFRP. Fuzzing is a kind of drilling defects observed when drilling CFRP/Al stack. It is caused by the flow of CFRP and Al chips during drilling 


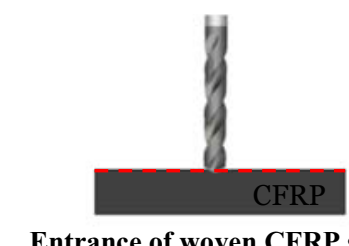

Entrance of woven CFRP sheet

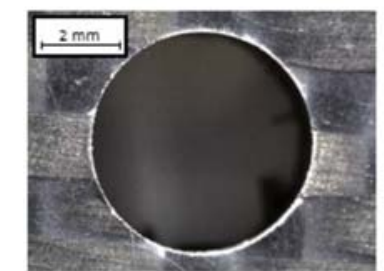

$\mathrm{V}_{\mathrm{f}}=9 \mathrm{~mm} / \mathrm{min}$ and $\mathrm{V}_{\mathrm{c}}=178.038 \mathrm{~m} / \mathrm{min}$
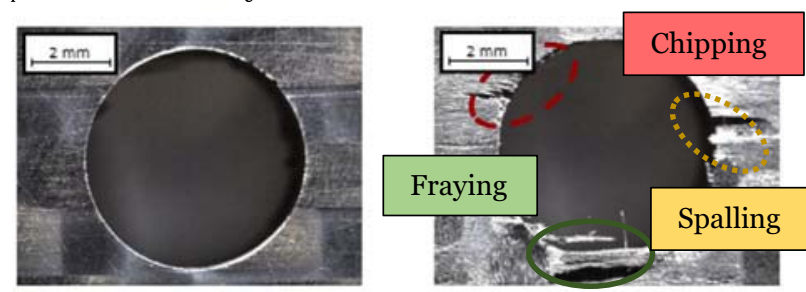

$\mathrm{V}_{\mathrm{f}}=15 \mathrm{~mm} / \mathrm{min}$ and $\mathrm{V}_{\mathrm{c}}=178.038 \mathrm{~m} / \mathrm{min}$
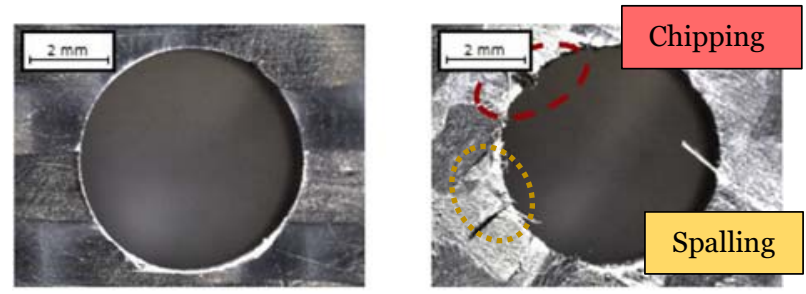

$V_{f}=21 \mathrm{~mm} / \mathrm{min}$ and $V_{c}=178.038 \mathrm{~m} / \mathrm{min}$
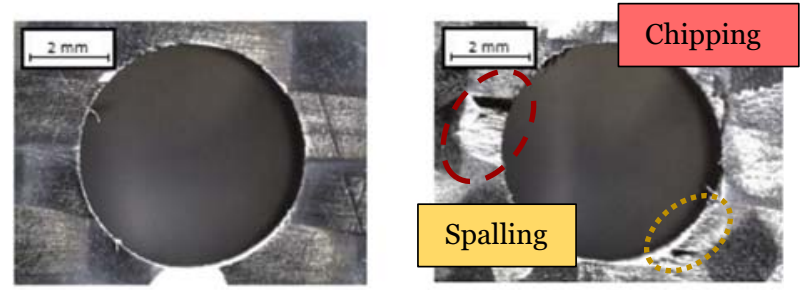

$\mathrm{V}_{\mathrm{f}}=15 \mathrm{~mm} / \mathrm{min}$ and $\mathrm{V}_{\mathrm{c}}=59.346 \mathrm{~m} / \mathrm{min}$

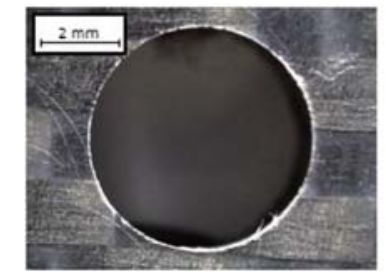

$\mathrm{V}_{\mathrm{f}}=15 \mathrm{~mm} / \mathrm{min}$ and $\mathrm{V}_{\mathrm{c}}=118.692 \mathrm{~m} / \mathrm{min}$

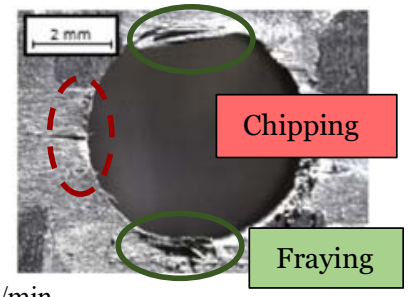

(a) CFRP sheet

Fig. 8 Macroscopic observation of woven CFRP and Al holes' sides. a CFRP sheet, b CFRP/Al stack, $\mathbf{c}$ Al/CFRP stack

which produced a washing out effect of the shim material [31]. It is presented at the exit side of woven CFRP when drilling CFRP/Al stack in the case of $V_{\mathrm{f}}=15 \mathrm{~mm} / \mathrm{min}$ and $V_{\mathrm{c}}=$ $59.346 \mathrm{~m} / \mathrm{min}$ although these values of cutting parameters are not the highest in this study. This case presents also the highest average of thrust force. The relation between the thermal degradation and the cutting conditions is not as indicated in the literature. Wang et al. noted that the drilling temperature has increased with the increase of spindle speed, and it has decreased with the increase of feed rate [3]. However, in our case, it seems that this conclusion does not work because we have drilled the stack using a very low value of machining parameters. Another phenomenon specific to metallic part figures in our study. It is the formation of burrs with a very small length at the exit side of the $\mathrm{Al}$ sheet when drilling CFRP/Al stack. This phenomenon is similar to the formation of chips. It nags the aerospace industry because burrs are very difficult to remove, and its removal can seriously damage the workpiece. In the literature, the formation of burr is related to the value of feed rate. Indeed, the length of burr at the exit side is higher than at the entrance one when drilling only $\mathrm{Al}$ sheet [33]. In our case, the burrs at the entrance side were disappeared, and the length of the obtained burrs is neglected compared with those obtained in the literature due to the lowest values of the utilized feed rate [34-36]. Regarding Al/CFRP stack, a neatly and sharp hole edge was obtained in the entrance and the exit side of Al sheet. We also noted the existence of CFRP chips on the exit side and the inside of $\mathrm{Al}$ holes which may influence the $\mathrm{Al}$ surface quality at the inside of the hole. To understand the influence of one-shot drilling operation on each configuration of hybrid stacks, the study of interior holes surfaces' quality is important because it influences the precision assembly of avionics components. For the $\mathrm{Al}$ layer, the holes' surface roughness $R_{\mathrm{a}}$ have been measured on the hole longitudinal direction. The value of $R_{\mathrm{a}}$ is the average of six measurements taken at different surface locations. Currently, the $\mathrm{Al}$ surface roughness was considered acceptable in aviation industries when it was lower than $1.6 \mathrm{~mm}$ [3]. In our case, it did not exceed $4.5 \mu \mathrm{m}$. Surface roughness results of the Al holes at different feed rate and cutting speed are shown in Fig. 9. The results revealed, for both $\mathrm{CFRP} / \mathrm{Al}$ and $\mathrm{Al} / \mathrm{CFRP}$ stacks, that $V_{\mathrm{f}}$ and $R_{\mathrm{a}}$ vary proportionally, and $V_{\mathrm{c}}$ and $R_{\mathrm{a}}$ vary inversely. Furthermore, the effect of cutting parameters on the surface roughness value is similar to thrust force evolution. The reason attributing to this remark is that, by increasing the feed rate, the voids surrounding the particles join up and cause chip segmentation. Indeed, increasing the cutting speed only leads to ductile tearing of the homogeneous metal chips [37]. For $\mathrm{Al} / \mathrm{CFRP}$, we notice that the interior surface state was improved compared with CFRP/Al. In fact, drilling the $\mathrm{Al}$ layer at the first reduces the surface roughness value despite the flow of CFRP chips through the already drilled hole which may lead to chip clogging [31]. However, CFRP is a bad conductor of heat. Drilling the composite layer at the first increases the tool's temperature, due to the absence of lubrication, and it damages the holes' interior surface quality. In order to investigate the interior surface morphologies for both $\mathrm{Al}$ and CFRP holes at various machining parameters, 


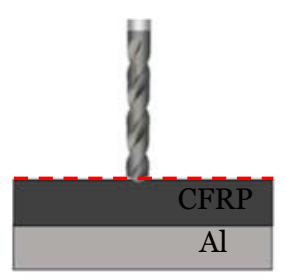

Entrance of woven CFRP sheet
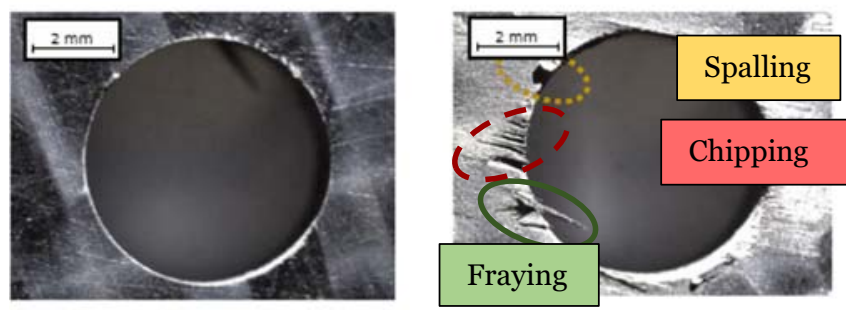

$V_{f}=9 \mathrm{~mm} / \mathrm{min}$ and $V_{c}=178.038 \mathrm{~m} / \mathrm{min}$
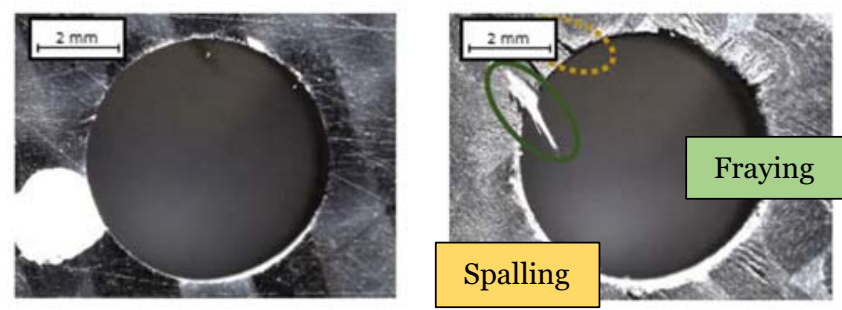

$V_{f}=15 \mathrm{~mm} / \mathrm{min}$ and $V_{c}=178.038 \mathrm{~m} / \mathrm{min}$
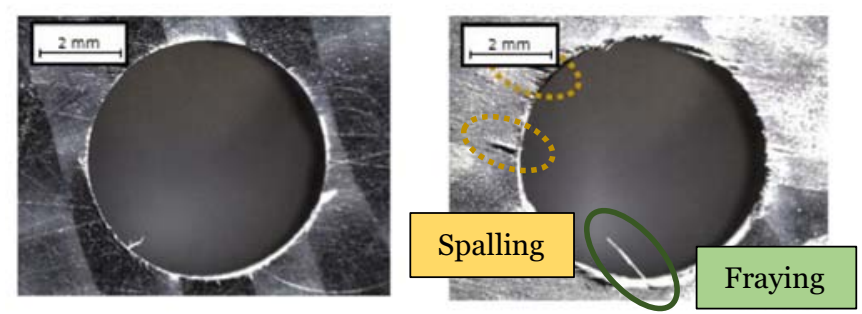

$V_{f}=21 \mathrm{~mm} / \mathrm{min}$ and $V_{c}=178.038 \mathrm{~m} / \mathrm{min}$
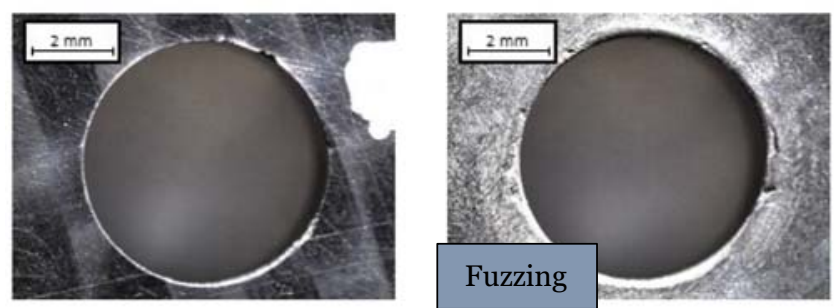

$\mathrm{V}_{\mathrm{f}}=15 \mathrm{~mm} / \mathrm{min}$ and $\mathrm{V}_{\mathrm{c}}=59.346 \mathrm{~m} / \mathrm{min}$
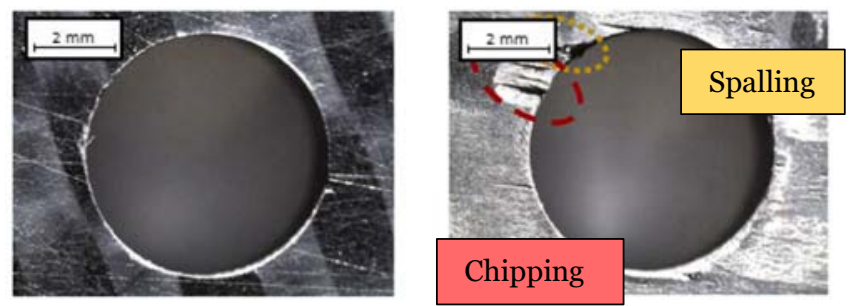
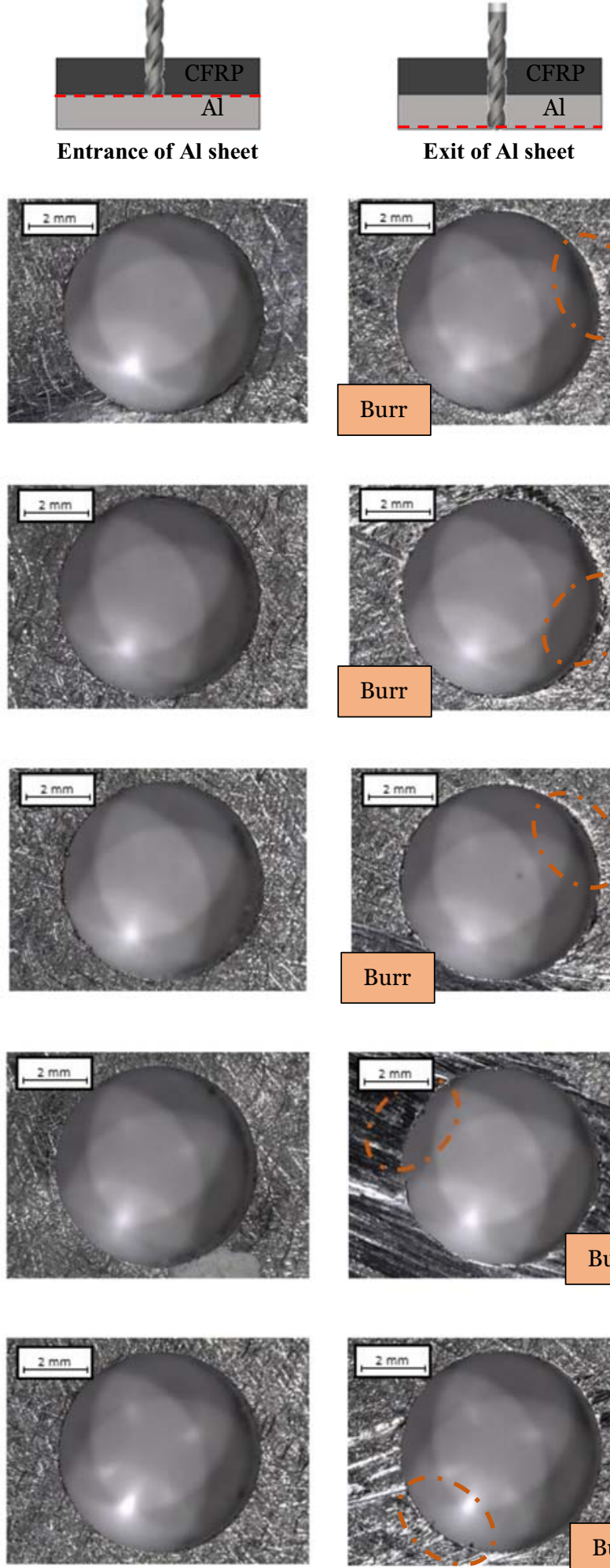

Exit of Al sheet
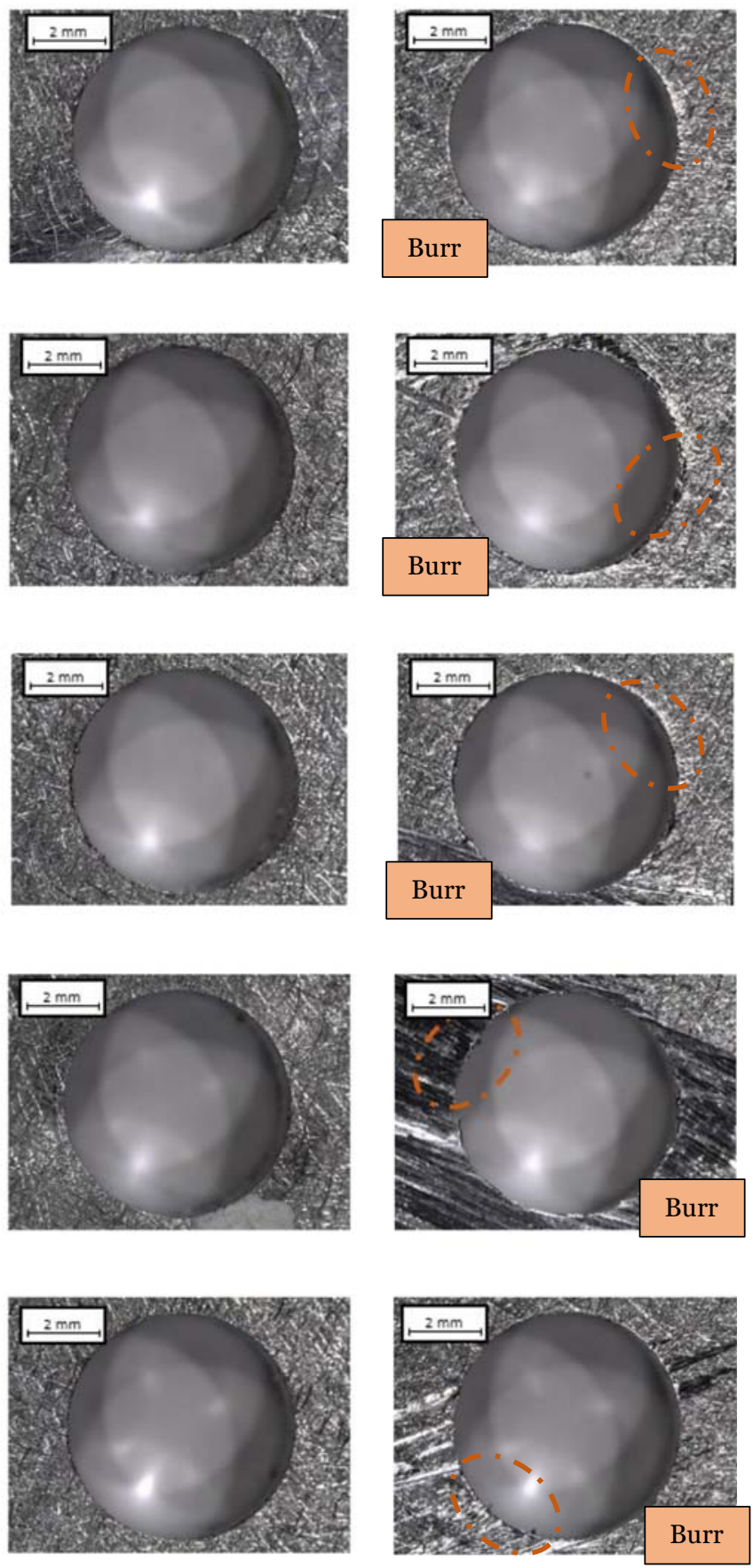

$V_{f}=15 \mathrm{~mm} / \mathrm{min}$ and $V_{c}=118.692 \mathrm{~m} / \mathrm{min}$

(b) $\mathrm{CFRP} / \mathrm{Al}$ stack

Fig. 8 (continued) 


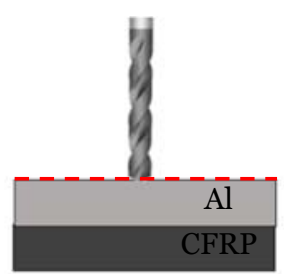

Entrance of Al sheet

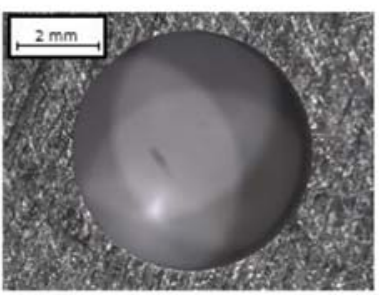

$\mathrm{V}_{\mathrm{f}}=9 \mathrm{~mm} / \mathrm{min}$ and $\mathrm{V}_{\mathrm{c}}=178.038 \mathrm{~m} / \mathrm{min}$
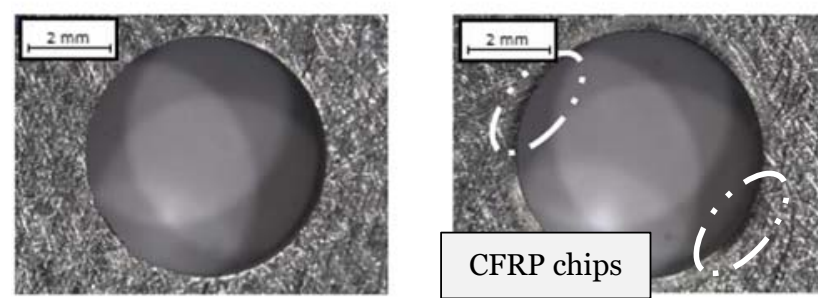

$\mathrm{V}_{\mathrm{f}}=15 \mathrm{~mm} / \mathrm{min}$ and $\mathrm{V}_{\mathrm{c}}=178.038 \mathrm{~m} / \mathrm{min}$
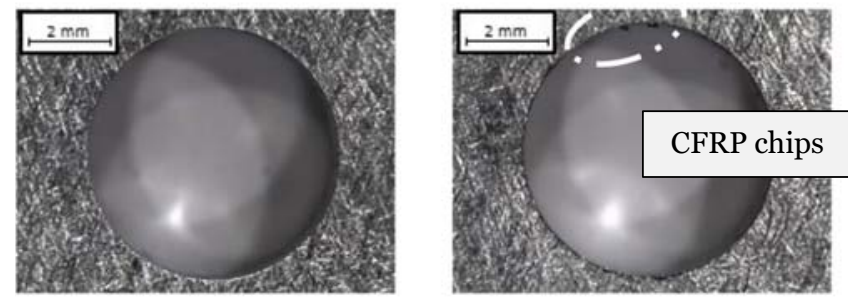

$V_{\mathrm{f}}=21 \mathrm{~mm} / \mathrm{min}$ and $V_{c}=178.038 \mathrm{~m} / \mathrm{min}$
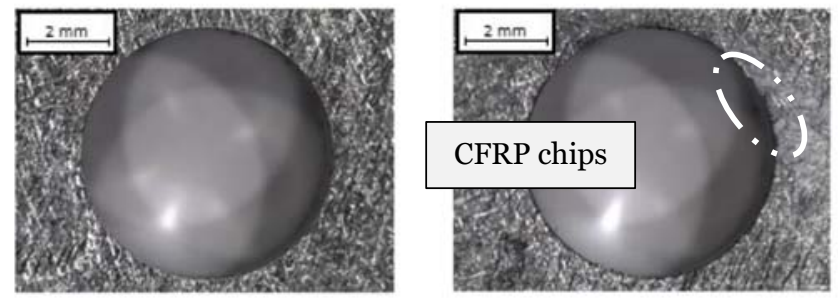

$V_{f}=15 \mathrm{~mm} / \mathrm{min}$ and $V_{c}=59.346 \mathrm{~m} / \mathrm{min}$
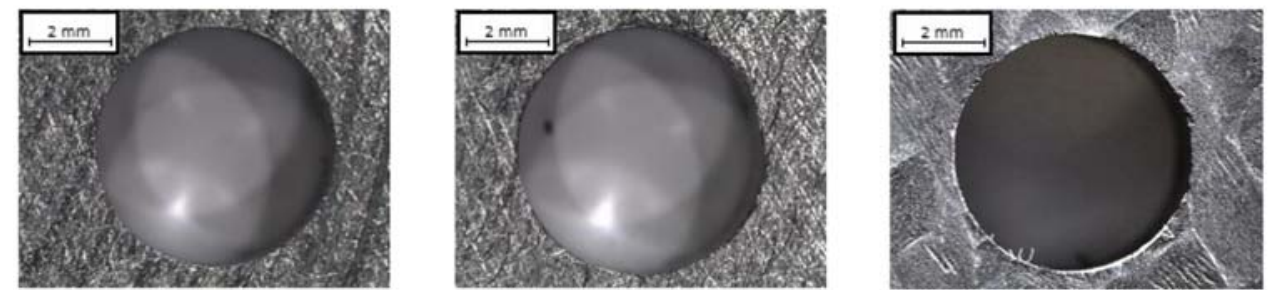

$\mathrm{V}_{\mathrm{f}}=15 \mathrm{~mm} / \mathrm{min}$ and $\mathrm{V}_{\mathrm{c}}=118.692 \mathrm{~m} / \mathrm{min}$

(c) Al/CFRP stack

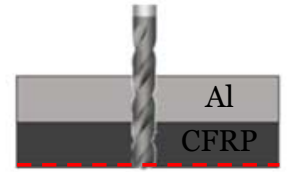

Exit of woven CFRP sheet
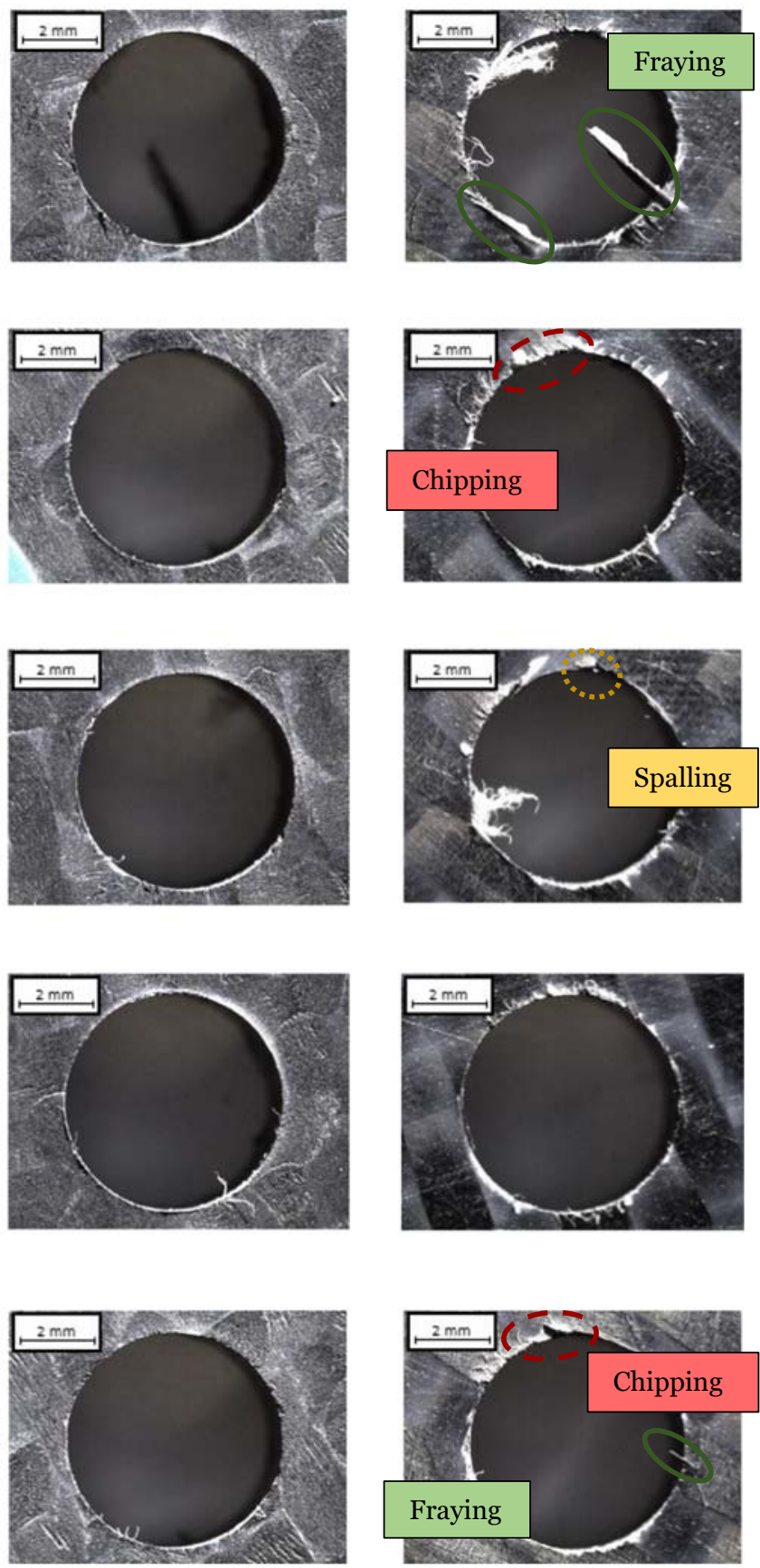

Fig. 8 (continued) 


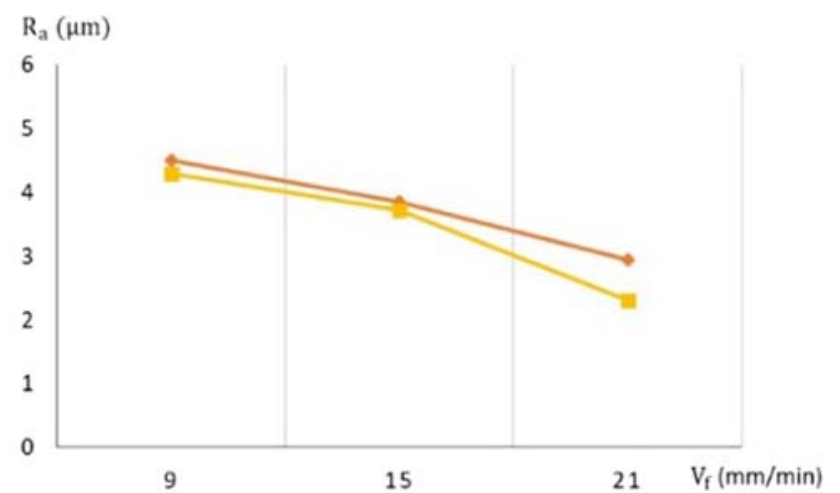

(a) $R_{a}=f\left(V_{f}\right)$ at $V_{c}=178.038 \mathrm{~m} / \mathrm{min}$

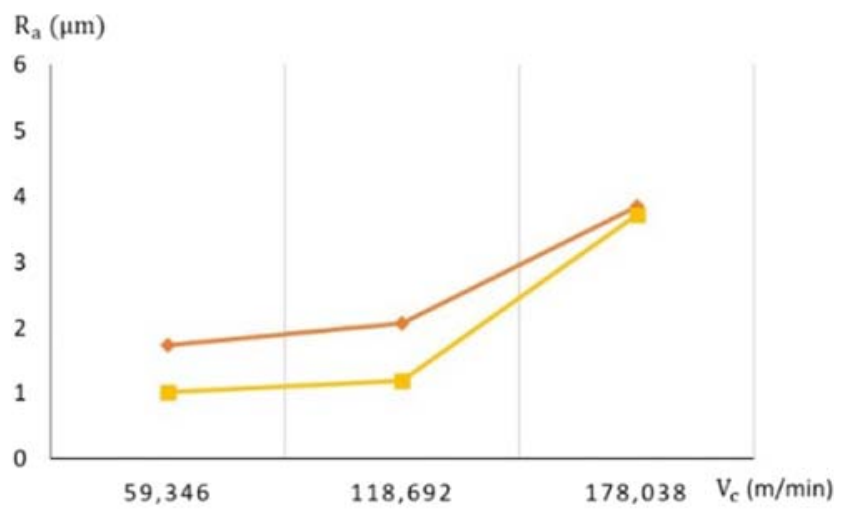

(b) $\mathrm{R}_{\mathrm{a}}=\mathrm{f}\left(\mathrm{V}_{\mathrm{c}}\right)$ at $\mathrm{V}_{\mathrm{f}}=15 \mathrm{~mm} / \mathrm{min}$

\section{$\ldots$ Al on the bottom of hybrid stack \\ - Al on the top of hybrid stack}

Fig. 9 Variation of $R_{\mathrm{a}}$ at various $V_{\mathrm{c}}$ and $V_{\mathrm{f}}$. (a) $R_{\mathrm{a}}=\mathrm{f}\left(V_{\mathrm{f}}\right)$ at $V_{\mathrm{c}}=$ $178.038 \mathrm{~m} / \mathrm{min}$. b $R_{\mathrm{a}}=\mathrm{f}\left(V_{\mathrm{c}}\right)$ at $V_{\mathrm{f}}=15 \mathrm{~mm} / \mathrm{min}$

macroscopic observations of the interior holes' surfaces were done using a scale of $1 \mathrm{~mm}$. Figure 10 presents $\mathrm{Al}$ holes' profiles at various cutting speed $V_{\mathrm{c}}$ and feed rate $V_{\mathrm{f}}$ for both stacks. Regarding the Al layer in the CFRP/Al stack, adhesive material appears in the hole's surface profile due to the absence of lubrication. Temperature increasement of the utilized drilling tool changes the $\mathrm{Al}$ mechanical characteristics and causes a bad material removal technique. This kind of defects is also observed in several research works [38, 39]. Smooth surfaces appear especially when drilling Al/CFRP stack. In fact, changing the drilling sequence of the hybrid stack influences the drilling process and the quality of drilled surfaces. It can be seen also other drilling defects like feed marks and surface cavities whenever drilling composite or aluminum layer first. The rotation of $\mathrm{Al}$ chips with the drill bit causes the apparition of grooves when drilling $\mathrm{Al}$ layer first in the hybrid stack. The biggest obtained groove width is near to $0.7 \mathrm{~mm}$ at $V_{\mathrm{f}}=15 \mathrm{~mm} / \mathrm{min}$ and $V_{\mathrm{c}}=118.692 \mathrm{~m} / \mathrm{min}$. We also
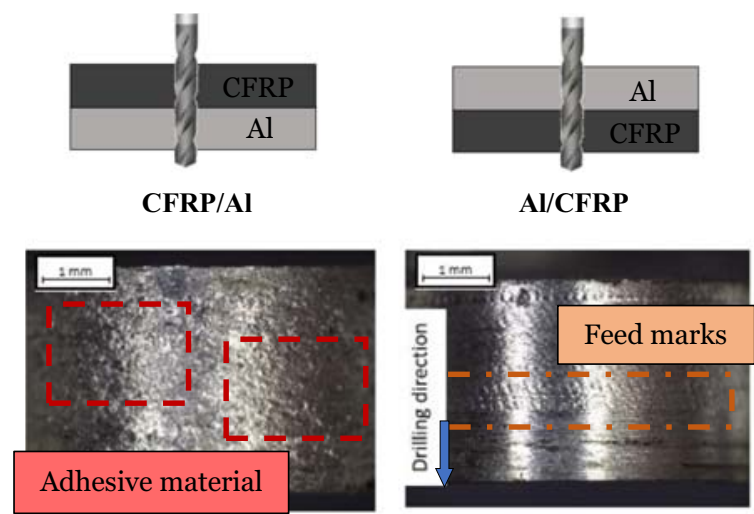

$\mathrm{V}_{\mathrm{f}}=9 \mathrm{~mm} / \mathrm{min}$ and $\mathrm{V}_{\mathrm{c}}=178.038 \mathrm{~m} / \mathrm{min}$
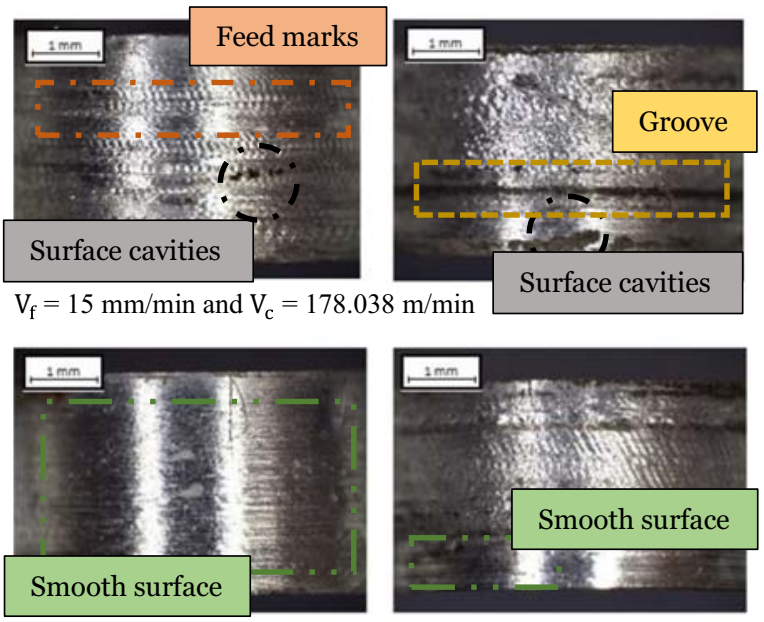

$V_{\mathrm{f}}=21 \mathrm{~mm} / \mathrm{min}$ and $V_{\mathrm{c}}=178.038 \mathrm{~m} / \mathrm{min}$

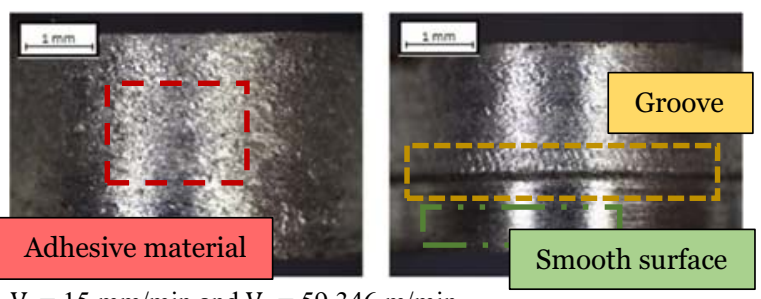

$\mathrm{V}_{\mathrm{f}}=15 \mathrm{~mm} / \mathrm{min}$ and $\mathrm{V}_{\mathrm{c}}=59.346 \mathrm{~m} / \mathrm{min}$
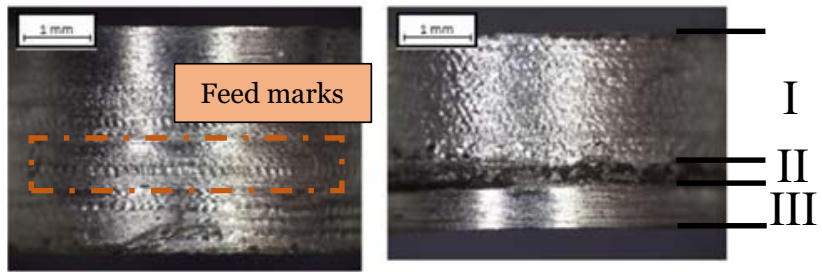

$\mathrm{V}_{\mathrm{f}}=15 \mathrm{~mm} / \mathrm{min}$ and $\mathrm{V}_{\mathrm{c}}=118.692 \mathrm{~m} / \mathrm{min}$

Fig. 10 Interior macroscopic observation of $\mathrm{Al}$ part

have the impression that the $\mathrm{Al}$ surface state in $\mathrm{Al} / \mathrm{CFRP}$ stack is subdivided into three parts: adhesive material, groove, and smooth surfaces. The apparition of smooth surfaces near to the hole exit side is related to the decreasing temperature of drilling tool caused by $\mathrm{Al}$ material. In fact, $\mathrm{Al}$ is a good heat conductor. It can therefore reduce the drilling toll's temperature. Regarding the composite part, Fig. 11 illustrates woven 

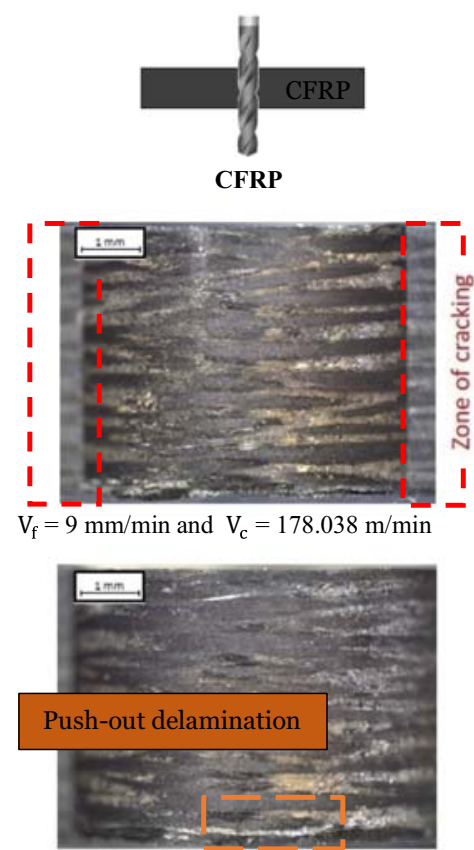

$\mathrm{V}_{\mathrm{f}}=15 \mathrm{~mm} / \mathrm{min}$ and $\mathrm{V}_{\mathrm{c}}=178.038 \mathrm{~m} / \mathrm{min}$

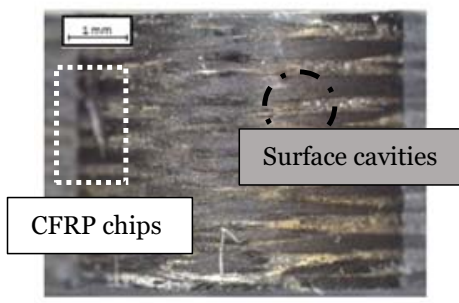

$\mathrm{V}_{\mathrm{f}}=21 \mathrm{~mm} / \mathrm{min}$ and $\mathrm{V}_{\mathrm{c}}=178.038 \mathrm{~m} / \mathrm{min}$

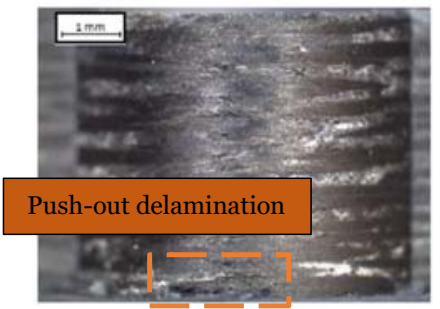

$\mathrm{V}_{\mathrm{f}}=15 \mathrm{~mm} / \mathrm{min}$ and $\mathrm{V}_{\mathrm{c}}=59.346 \mathrm{~m} / \mathrm{min}$

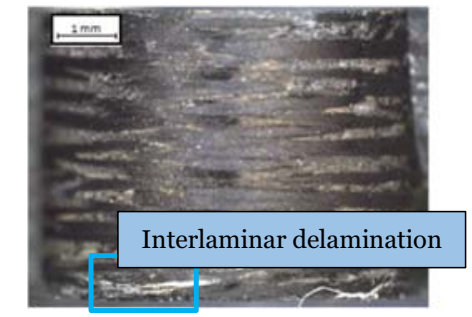

$\mathrm{V}_{\mathrm{f}}=15 \mathrm{~mm} / \mathrm{min}$ and $\mathrm{V}_{\mathrm{c}}=118.692 \mathrm{~m} / \mathrm{min}$

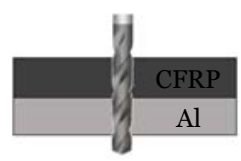

CFRP/Al
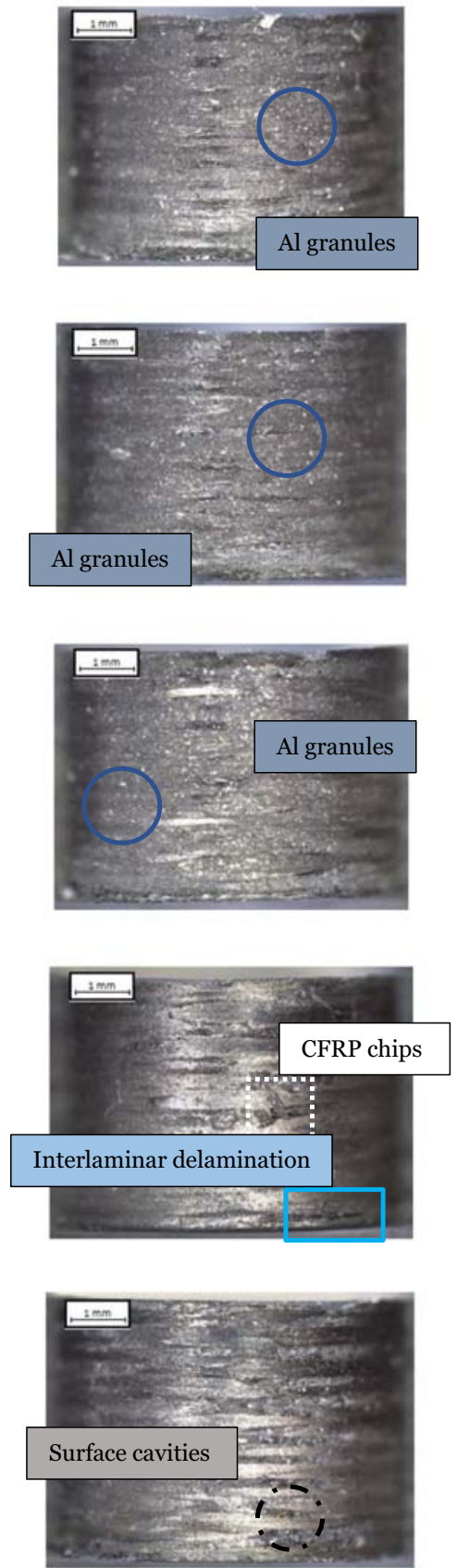

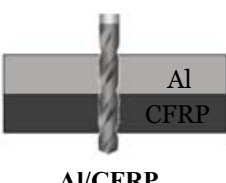

Al/CFRP
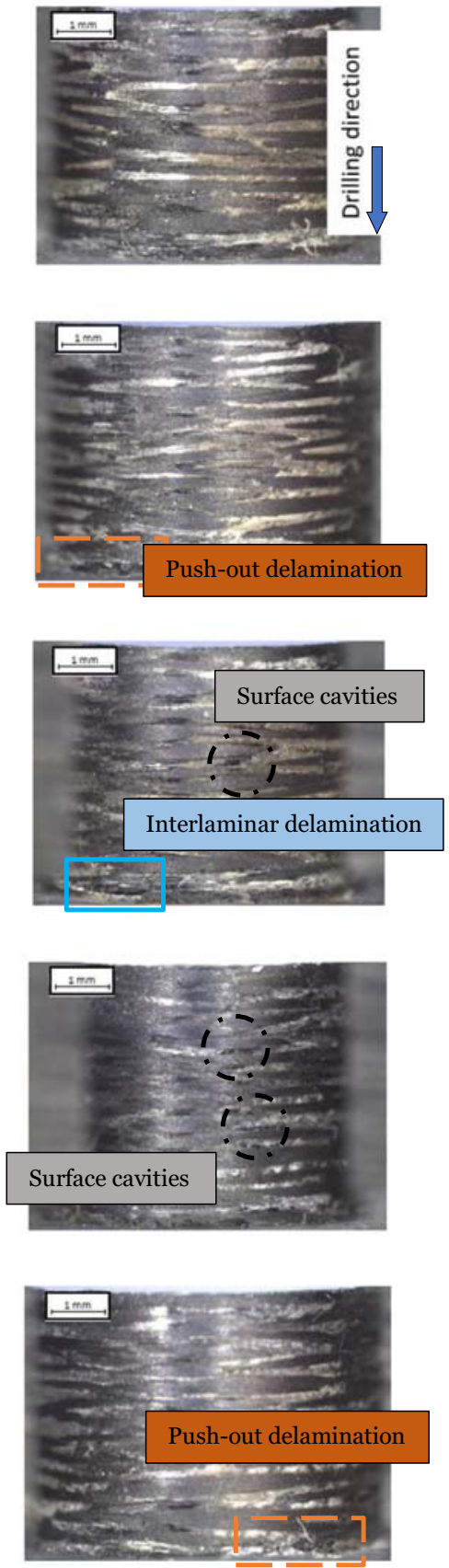

Fig. 11 Interior macroscopic observation of woven CFRP part

CFRP holes' profiles at various cutting speed $V_{\mathrm{c}}$ and feed rate $V_{\mathrm{f}}$ when drilling CFRP sheet, CFRP/Al, and Al/CFRP stacks. Whatever the kind of drilling process, the cut woven CFRP profiles show drilling defects like surface cavities, interlaminar delamination, and push-out delamination. These damages are similar to those obtained when drilling unidirectional CFRP [40].

As our eyes are too small to notice the difference between surface morphologies, SEM analysis were made on woven CFRP holes under different drilling process using $V_{\mathrm{f}}=$ 


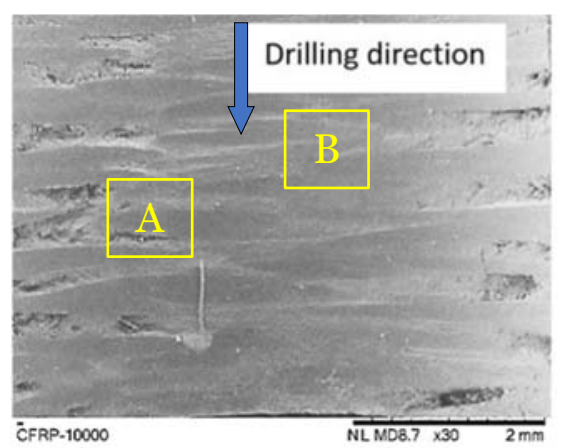

(a) CFRP

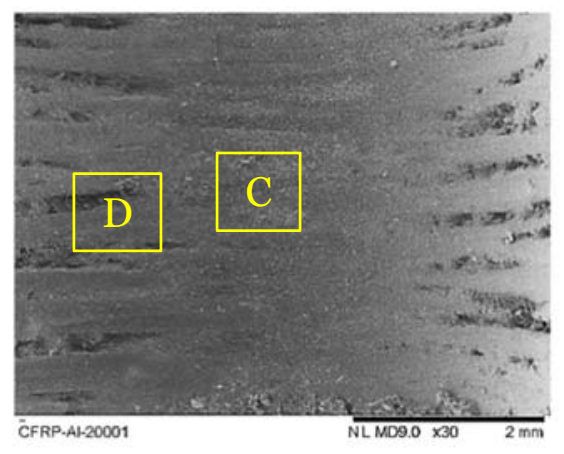

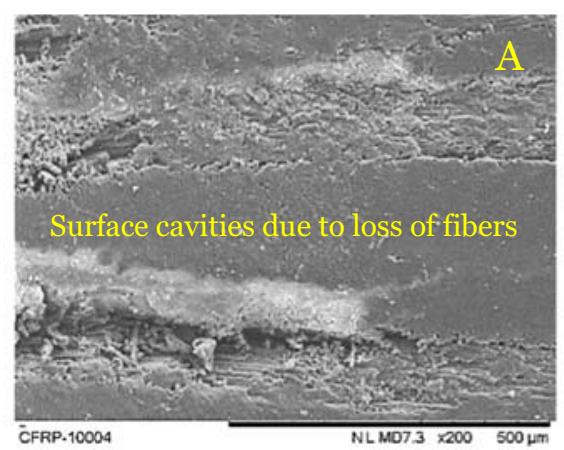

ĊFRP. 10004

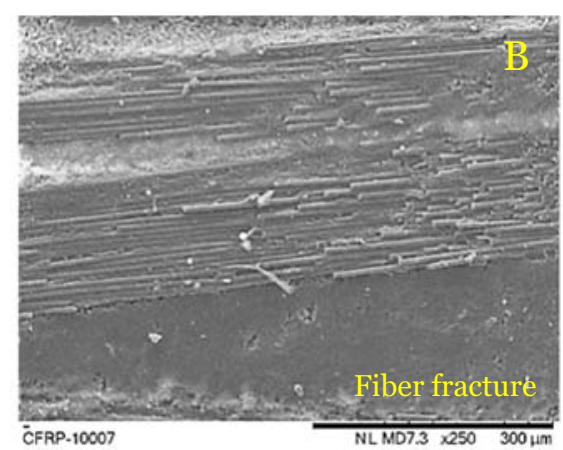

CFRP-10007
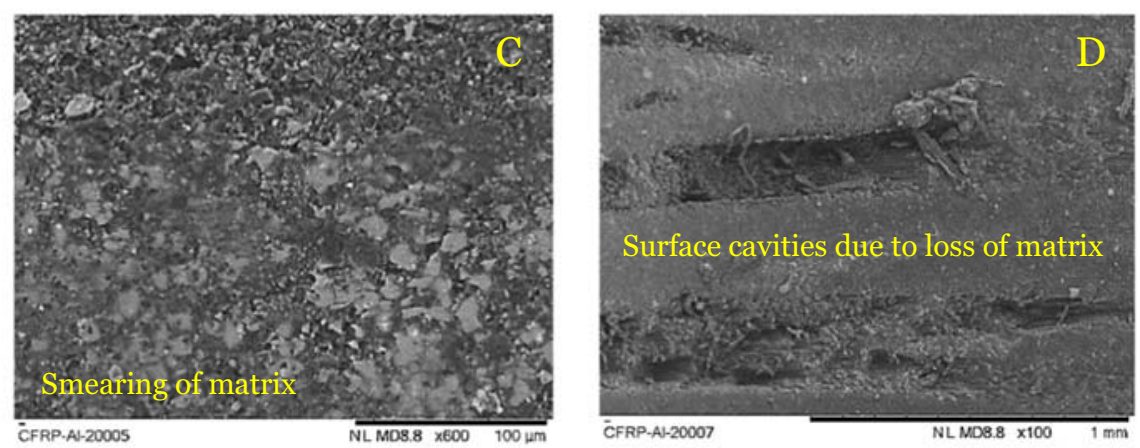

(b) $\mathrm{CFRP} / \mathrm{Al}$
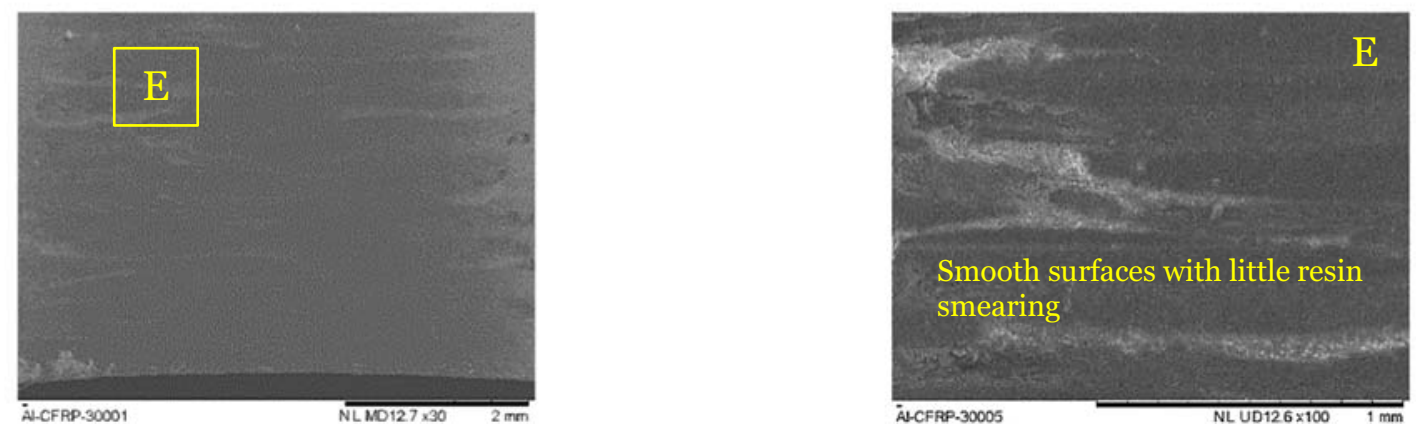

(c) Al/CFRP

Fig. 12 SEM morphologies of CFRP holes at $V_{\mathrm{f}}=15 \mathrm{~mm} / \mathrm{min}$ and $V_{\mathrm{c}}=59.346 \mathrm{~m} / \mathrm{min}$

$15 \mathrm{~mm} / \mathrm{min}$ and $V_{\mathrm{c}}=59.346 \mathrm{~m} / \mathrm{min}$. SEM observations are presented in Fig. 12. It can be noted that surface cavities, which are presented in figure $\mathrm{A}$ and $\mathrm{D}$, could be created due to loss of fibers or matrix. They are localized on both sides of the hole. Fractured fibers exist in the middle like presented in figure B. Eneyew et al. [41] have noted that the drilling of unidirectional CFRP $\left[90^{\circ}\right]_{33}$ provide the most serious defects in two specific regions which are located at 135 and $315^{\circ}$ from hole's diameter. The selected hole's diameter is perpendicular to composite fiber direction. It seems logic in our case to found surface cavities at -45 and $45^{\circ}$ from hole's diameter because the utilized CFRP material is composed of weaving fibers initially oriented at 0 and $90^{\circ}$. Regarding the observed holes, it can be noted that adding $\mathrm{Al}$ sheet on the top or on the bottom of CFRP sheet reduces the size of surface cavities. Indeed, the surface cavities are practically absent in the case of Al/CFRP stack, and the surface quality is smooth with little resin smearing, like presented in figure $\mathrm{E}$, because the CFRP layer exist between two supports. However, the existence of Al layer on the bottom of CFRP layer causes matrix smearing like presented in figure $\mathrm{C}$ due to the flow of $\mathrm{Al}$ chips during drilling process.

\section{Conclusion}

In this paper, a study of the influence of adding AA 2189 sheet to AS-4 woven CFRP sheet at various positions have been 
carried out using specific condition of cutting parameters. The choice of materials was based on what used nowadays in the aircraft structure. This work gives some idea about the influence of machining conditions on hybrid stack drilling defects. The following conclusions can be drawn. Layers' positions in hybrid stacks do no effect thrust force evolution. Its increased value is related to enhanced risk of woven CFRP epoxy matrix thermal degradation when drilling CFRP/Al stack, and it causes also a bad roughness surface of the $\mathrm{Al}$ holes. Cutting speed has been the most responsible one of the delamination phenomenon augmentations, and it is the most important factor influencing the thrust force no matter for woven CFRP or $\mathrm{Al}$ due to feed rate low values in our study. Changing the material order in the hybrid stack influences the holes surface quality. Making Al layer on the bottom causes the smearing of composite matrix. However, it causes groove in the Al hole when it is on the top. Adding Al layer on the top of woven CFRP reduces the apparition of drilling defects and delamination phenomenon especially at the hole exit side. So, drilling composite material between two supports improves hole quality even with the use of twist drill bit. As a perspective, it seems very important to study the effect of temperature evolution when drilling hybrid stacks on holes surface quality in future works and to validate our results by analytical and numerical modeling.

Acknowledgments This work is partially supported by Laboratory of Applied Fluid Mechanics, Environment and Process Engineering. Sincere thanks are extended to Zodiac aerospace for the CFRP plates, Laboratory of Innovation Technology for the drills and their support for doing experimental tests in good conditions and Toulouse University for the realization of SEM observations. The authors also gratefully acknowledge the helpful comments and suggestions of the reviewers, which have improved the presentation.

\section{References}

1. Geng D, Liu Y, Shao Z et al (2020) Delamination formation and suppression during rotary ultrasonic elliptical machining of CFRP. Compos B 183:107698. https://doi.org/10.1016/j.compositesb. 2019.107698

2. Jia ZY, Chen C, Wang FJ, Ma JW, Yang F (2018) Threedimensional oblique cutting model for sub-surface damage analysis in CFRP/Ti stack composite machining. Int J Adv Manuf Technol 96:643-655. https://doi.org/10.1007/s00170-018-1626-5

3. Wang CY, Chen YH, An QL et al (2015) Drilling temperature and hole quality in drilling of CFRP/aluminum stacks using diamond coated drill. Int J Precis Eng Manuf 16(8):1689-1697. https://doi. org/10.1007/s12541-015-0222-y

4. Soutis C (2015) Introduction: engineering requirements for aerospace composite materials, Elsevier. Polymer Compos Aerospace Industry. https://doi.org/10.1016/B978-0-85709-523-7.00001-3

5. Feito N, Diaz-Alvarez J, Diaz-Alvarez A et al (2014) Experimental analysis of the influence of drill point angle and wear on the drilling of woven CFRPs. Materials 7:4258-4271. https://doi.org/10.3390/ ma7064258
6. Qui X, Li P, Niu Q et al (2018) Influence of machining parameters and tool structure on cutting force and hole wall damage in drilling CFRP with stepped drills. Int J Adv Manuf Technol 97:857-865. https://doi.org/10.1007/s00170-018-1981-2

7. Li M, Leung Soo S, Aspinwall DK et al (2018) Study on tool wear and work piece surface integrity following drilling of CFRP laminates with variable feed rate strategy. Sci Direct Proc CIRP 71:407412

8. Turki Y, Habak M, Velasco R et al (2014) Experimental investigation of drilling damage and stitching effects on the mechanical behavior of carbon/epoxy composites. Int J Mach Tools Manuf 87:61-72

9. Mahdi A, Turki Y, Bouaziz Z, Habak M., Bouami S.E. (2019) Experimental effect of cutting parameters and tool geometry in drilling woven CFRP, advances in mechanical engineering and mechanics. CoTuMe 2018. Lecture notes in mechanical engineering. Springer, Cham doi: https://doi.org/10.1007/978-3030-19781-0_17

10. Mrazova M (2013) Advanced composite materials of the future in aerospace industry. INCAS BULLETIN 5(3):139-150 ISSN 20668201

11. Luo B, Li Y, Zhang K, Cheng H, Liu S (2014) A novel prediction model for thrust force and torque in drilling interface region of CFRP/Ti stacks. Int J Adv Manuf Technol 81:1497-1508. https:// doi.org/10.1007/s00170-015-7294-9

12. Dang J, Zou F, Cai X, An Q, Ming W, Chen M (2019) Experimental investigation on mechanical drilling of a newly developed CFRP/Al co-cured material. Int J Adv Manuf Technol 106:993-1004. https:// doi.org/10.1007/s00170-019-04659-1

13. Liu S, Qi Z, Li Y et al (2016) On full life-cycle instantaneous force predicting when drilling CFRP-metal stacks. Int J Adv Manuf Technol 88:651-661. https://doi.org/10.1007/s00170-016-8794-y

14. Fernandez-Vidad SR, Fernandez-Vidad S, Batista M et al (2018) Tool Wear mechanism in cutting of stack CFRP/UNS A97075. Materials 11:1276. https://doi.org/10.3390/ma11081276

15. Hassan MH, Abdullah J, Mahmud AS et al (2018) Effects of twist drill geometry and drilling parameters on CFRP-aluminum stack up in single shot drilling. SciFed J Mater Res Lett 2(2):1-14

16. El Bouami S, Habak M, Velasco R et al (2017) Tool geometry optimization for drilling CFRP/Al-Li stacks with a lightning strike protection. AIP Conference Proc 1896:090009. https://doi.org/10. 1063/1.5008116

17. El Bouami S, Habak M, Franz G et al (2016) Effect of tool geometry and cutting parameters on delamination and thrust forces in drilling CFRP/Al-Li. AIP Conference Proc 1769:080012. https:// doi.org/10.1063/1.4963487

18. Caggiano A, Napolitano F, Nelec L et al. (2019) Study on thrust force and torque sensor signals in drilling of Al/CFRP stacks for aeronautical applications, 12th CIRP Conference on Intelligent Computation in Manufacturing Engineering, 18-20 July 2018, Italy, Procedia CIRP, vol. 79, pp. 337-342

19. Angelone R, Caggiano A, Improta I et al. (2019) Characterization of hole quality and temperature in drilling of $\mathrm{Al} / \mathrm{CFRP}$ stacks under different process condition, 12th CIRP Conference on Intelligent Computation in Manufacturing Engineering, 18-20 July 2018, Italy, Procedia CIRP, vol. 79, pp. 319-324

20. Robbany F, Pramujati B, Suhardjono et al. (2019) Multi response prediction of cutting force and delamination in carbon Fiber reinforced polymer using backpropagation neural network-genetic algorithm, AIP Conference Proceedings 2114, 030012. doi: https:// doi.org/10.1063/1.5112416

21. Feito N, Milani AS, Muñoz-Sánchez A (2015) Drilling optimization of woven CFRP laminates under different tool wear conditions: a multi-objective design of experiments approach. Struct Multidiscip Optim 53:239-251. https://doi.org/10.1007/s00158015-1324-y 
22. Harranen H, Kers J, Preden JS et al (2014) Embedded electronics influence on the strength of carbon fiber laminate. Adv Mater Res 905:239-243. https://doi.org/10.4028/www.scientific.net/AMR. 905.239

23. Kers J and Majak J (2008) Modelling a new composite from a recycled GFRP, Mechanics of Composite Materials, vol. 44, no. 6

24. Ashrafi SA, Sharif S, Farid AA et al (2014) Performance evaluation of carbide tools in drilling CFRP-Al stacks. J Compos Mater 48(17):2071-2084. https://doi.org/10.1177/0021998313494429

25. Brinksmeier E, Fangmann S, Rentsch R (2011) Drilling of composites and resulting surface integrity. CIRP Annals Manuf Technol 60: $57-60$

26. Neugebauer R, Ben-Hanan U, Ihlenfeldt S et al (2012) Acoustic emission as a tool for identifying drill position in fiber-reinforced plastic and aluminum stacks. Int J Mach Tools Manuf 57:20-26

27. Park K-H, Beal A, Kim D et al (2011) Tool wear in drilling of composite/titanium stacks using carbide and polycrystalline diamond tools. Wear 271:2826-2835

28. Zitoune R, Krishnaraj V, Collombet F (2010) Study of drilling of composite material and aluminum stack, Elsevier. Compos Struct 92:1246-1255

29. Merzouki J, Poulachon G, Rossi F et al. (2017) Method of hole shrinkage radial forces measurement in Ti6Al4V drilling, $16^{\text {th }}$ CIRP Conference on Modelling of Machining Operations, Procedia CIRP, vol. 58, pp. 629-634

30. Turki Y, Habak M, Velasco K et al (2014) Influence of cutting forces and damage on 2D and 3D carbon/epoxy composites in drilling. Key Eng Mater 611-612:1217-1225. https://doi.org/10. 4028/www.scientif.net/KEM.611-612.1217

31. Wertheim R, Ben-Hanan U, Ihlenfeldt S et al (2012) Acoustic emission for controlling drill position in fiber-reinforced plastic and metal stacks. CIRP Ann Manuf Technol 61:75-78. https://doi.org/ 10.1016/j.cirp.2012.03.003

32. Aboura Z (1993) Etude du processus de délaminage mode I, mode II et mode mixte (I+II) de matériaux composites à renforts tissés à différentes vitesses de sollicitation, thesis book, Compiègne

33. Wei T, Jian H, Wenhe L et al (2016) Formation of interlayer gap and control of interlayer burr in dry drilling of stacked aluminum alloy plates. Chin J Aeronaut 19(1):283-291. https://doi.org/10.1016/j. cja.2015.11.002

34. Brinksmeier E and Fangmann S (2009) Burr and cap formation by orbital Drilling of Aluminum, proceedings of the CIRP international conference on burrs, pp. 31-44, University of Kaiserslautern, Germany

35. Soo SL, Abdelhafeez AM, Li M et al (2017) The drilling of carbon fiber composite-aluminum stacks and its effect on hole quality and integrity, proceedings of the institution of mechanical engineers, Part B: Journal of Engineering Manufacture, pp 1-9. https://doi. org $/ 10.1177 / 0954405417728312$

36. Heisela U and Pfeifrothb $\mathrm{T}$ (2012) Influence of point angle on drill hole quality and machining forces when drilling CFRP, science direct, 5th CIRP conference on high performance cutting, pp. $471-476$

37. El Gallab M, Sklad M (1998) Machining of Al/SiC particulate metal matrix composites part II: workpiece surface integrity, Elsevier. J Mater Process Technol 83:277-285

38. Zhang L, Liu Z, Tian W, Liao W (2015) Experimental studies on the performance of different structure tools in drilling CFRP/Al alloy stacks. Int J Adv Manuf Technol 81:241-251. https://doi.org/10. 1007/s00170-015-6955-z

39. Uddin M, Basak A, Pramanik A et al (2018) Evaluating hole quality in drilling of $\mathrm{Al} 6061$ alloys. Materials 11:2443. https://doi.org/10. 3390/ma11122443

40. Xu J, Zhou L, Chen M et al (2019) Experimental study on mechanical drilling of carbon / epoxy composite - Ti6Al4V stacks. Mater Manuf Process. https://doi.org/10.1080/10426914.2019.1594275

41. Eneyew ED, Ramulu M (2014) Experimental study of surface quality and damage when drilling unidirectional CFRP composites. J Mater Res Technol 3(4):354-362. https://doi.org/10.1016/j.jmrt. 2014.10 .003

Publisher's note Springer Nature remains neutral with regard to jurisdictional claims in published maps and institutional affiliations. 